\title{
Which eHealth interventions are most effective for smoking cessation? A systematic review
}

This article was published in the following Dove Press journal:

Patient Preference and Adherence

\author{
Huyen Phuc Do',2 \\ Bach Xuan Tran ${ }^{3,4}$ \\ Quyen Le Pham ${ }^{5}$ \\ Long Hoang Nguyen ${ }^{6,7}$ \\ Tung Thanh Tran² \\ Carl A Latkin ${ }^{3}$ \\ Michael P Dunne 1,8 \\ Philip RA Baker' \\ 'School of Public Health and Social \\ Work, Queensland University \\ of Technology, Brisbane, QLD, \\ Australia; ${ }^{2}$ Institute for Global Health \\ Innovations, Duy Tan University, \\ Danang, Vietnam; ${ }^{3}$ Department of \\ Health, Behaviours and Society, \\ Johns Hopkins Bloomberg School \\ of Public Health, Baltimore, MD, \\ USA; ${ }^{4}$ Institute for Preventive \\ Medicine and Public Health, Hanoi \\ Medical University, Hanoi, Vietnam; \\ ${ }^{5}$ Department of Internal Medicine, \\ Hanoi Medical University, Hanoi, \\ Vietnam; ${ }^{6}$ Department of Public \\ Health Sciences, Karolinska Institutet, \\ Stockholm, Sweden; ${ }^{7}$ Center of \\ Excellence in Behavioral Medicine, \\ Nguyen Tat Thanh University, Ho \\ Chi Minh City, Vietnam; ${ }^{8}$ Institute for \\ Community Health Research, Hue \\ University, Hue, Vietnam
}

Correspondence: Huyen Phuc Do School of Public Health and Social Work, Queensland University of Technology, Victoria Park Road, Kelvin Grove, Brisbane, QLD 4059, Australia

$\mathrm{Tel}+84977109186$

Email phuchuyen@gmail.com
Purpose: To synthesize evidence of the effects and potential effect modifiers of different electronic health (eHealth) interventions to help people quit smoking.

Methods: Four databases (MEDLINE, PsycINFO, Embase, and The Cochrane Library) were searched in March 2017 using terms that included "smoking cessation", "eHealth/mHealth" and "electronic technology" to find relevant studies. Meta-analysis and meta-regression analyses were performed using Mantel-Haenszel test for fixed-effect risk ratio (RR) and restricted maximumlikelihood technique, respectively. Protocol Registration Number: CRD42017072560.

Results: The review included 108 studies and 110,372 participants. Compared to nonactive control groups (eg, usual care), smoking cessation interventions using web-based and mobile health (mHealth) platform resulted in significantly greater smoking abstinence, RR 2.03 (95\% CI 1.7-2.03), and RR 1.71 (95\% CI 1.35-2.16), respectively. Similarly, smoking cessation trials using tailored text messages (RR 1.80, 95\% CI 1.54-2.10) and web-based information and conjunctive nicotine replacement therapy (RR 1.29, 95\% CI 1.17-1.43) may also increase cessation. In contrast, little or no benefit for smoking abstinence was found for computer-assisted interventions (RR 1.31, 95\% CI 1.11-1.53). The magnitude of effect sizes from mHealth smoking cessation interventions was likely to be greater if the trial was conducted in the USA or Europe and when the intervention included individually tailored text messages. In contrast, high frequency of texts (daily) was less effective than weekly texts.

Conclusions: There was consistent evidence that web-based and mHealth smoking cessation interventions may increase abstinence moderately. Methodologic quality of trials and the intervention characteristics (tailored vs untailored) are critical effect modifiers among eHealth smoking cessation interventions, especially for web-based and text messaging trials. Future smoking cessation intervention should take advantages of web-based and mHealth engagement to improve prolonged abstinence.

Keywords: effectiveness, eHealth, smoking cessation intervention, mHealth, website, computer

\section{Plain language summary}

\section{Which eHealth interventions help people to stop smoking?}

Background: Smoking is expected to kill 8 million people per year by 2030. New web-based and mobile phone applications are attractive platforms to help people quit. Electronic health (eHealth)/mobile health (mHealth) approaches (ie, health care practice assisted by electronic processes and communication) are easy to use, affordable, flexible and have a wide reach. We sought to identify which strategies work the best.

Study characteristics: Up to March 2017, this review found 108 trials from over 110,000 participants. We examined those that were web-based including those integrated with medication, mobile-based, SMS texts, computer-assisted and others like "video doctor".

Key results: In combined results, web-based approaches and those using mobile-based approaches led to higher six-month quit rates than a nonactive comparison (eg, usual care, 
assessment only). Quit smoking programs with personalized messages were also likely to help. Other computer-assisted programs had lower quit rates and daily messages lower than weekly messages.

Quality of the evidence: The evidence was moderate to low quality. Studies at high risk of bias showed higher quit rates.

Implications for practice: Web-based and mobile health strategies help people quit smoking, although their effects are modest over a short period.

Implications for research: New and emerging interventions should be evaluated. More research should be conducted in low and middle-income countries.

\section{Introduction}

Smoking is a modifiable cause of mortality and morbidity. Globally, 5\% of all deaths are attributed to smoking and 14\% of adults over 30 years old are at risk of premature death from smoking-related diseases. ${ }^{1}$ It is predicted that tobacco use will be responsible for more than 8 million deaths worldwide per year by 2030 if effective interventions are not implemented. ${ }^{2}$ A reasonable approach to tackle the global burden of smoking could be to expand the accessibility of cessation programs to all smokers. Electronic health (eHealth) approaches are considered to have many advantages including 1) easy accessibility regardless of time and place; 2) affordability and efficient delivery; 3 ) wider reach to large populations; and 4) flexibility to enable proactive and tailored messages and allow matching to target user characteristics (for example, by age, sex, education, or quit plan). ${ }^{3}$ Thus, recent research has suggested that innovative, technology-based strategies can be applied to improve smoking cessation. ${ }^{4}$

The technology landscape is changing rapidly, with the growth of smartphone ownership globally, reaching approximately one-third of the world's population. In 2016 there were an estimated 2.16 billion users with access to 70,000 health and fitness apps and 79,000 medical apps via the Apple App Store ${ }^{\circledR}$ and Google Play store ${ }^{\circledR}{ }^{5}$ This revolution in technology also offers great opportunities for clinical research and interventions using mobile health, defined as "medical and public health practice supported by mobile devices", 3,6 Mobile phone text messaging services have been piloted and implemented in some tobacco cessation programs. ${ }^{7-11}$ One limitation of this approach has been a focus on text message reminders for quitting smoking, while other potentially useful tools such as abstinence behavior tracking, peer group chats, and distractions remain unused. ${ }^{12}$ Perhaps the most serious limitation of mobile health (mHealth) technology assessment to date is the lack of engagement with underserved populations (eg, low-literacy groups, geographical areas with limited internet access, or poorer communities where there are multiple users per device). ${ }^{13}$

Most of the previous systematic reviews of eHealth interventions for smoking cessation have investigated the effects of specific devices upon smoking abstinence outcomes including internet/web-based cessation program, ${ }^{14-21}$ text messaging system, ${ }^{22-24}$ and computer-based program. ${ }^{25}$ The most recent systematic review pooled results from 67 studies and found a moderate effect on smoking cessation using web-based/internet penetration with behavioral support, compared to an nonactive control group (risk ratio [RR] 1.69, 95\% CI 1.30-2.18). ${ }^{20}$ That review failed to detect the effect of web-based smoking cessation compared to active control group (RR 0.92, 95\% CI 0.78-1.09). ${ }^{20}$ Similarly, another systematic review of 40 internet-based smoking cessation interventions suggested a moderate effect of the smoking cessation intervention using web-based/internet penetration (eg, websites, e-mail, and multimedia component) compared to assessment-only groups (RR 1.48, 95\% CI 1.11-2.78) and a significant strong effect of systems that use interactive webpages compared to print materials (RR 2.1, 95\% CI 1.42-2.97). ${ }^{19}$ Computer-delivered interventions were also found to improve knowledge, attitudes, and intentions related to various health behaviors including smoking cessation. ${ }^{25}$ Although web-based smoking cessation interventions are generally found to be effective in decreasing smoking prevalence in many studies, heterogeneity in effect sizes is a significant concern. ${ }^{26}$

Previous systematic reviews have focused on identifying and evaluating the mediators of intervention effects that use text messaging to improve smoking cessation. ${ }^{22-24,26}$ A Cochrane review that pooled data from 12 studies indicated that mobile phone-based smoking interventions resulted in a moderate increase in cessation (RR 1.67). ${ }^{24}$ A meta-analysis (in 2015), pooled effects shown in 35 studies using text messaging to improve health behaviors including smoking cessation, suggested that interventions, which are not theoretically grounded, have supplementary intervention activities and have 6-12 months duration, and are most effective. In contrast, tailoring, targeting, or personalization of SMS content did not moderate the effect of the interventions. ${ }^{27}$ A related issue is that there is a dearth of knowledge on how to improve user acceptance of mHealth smoking cessation interventions. ${ }^{12}$ The most comprehensive systematic review (conducted in 2012) on the efficacy of various eHealth interventions to improve smoking abstinence from 60 studies found that internet and other electronic platforms improved smoking cessation outcomes compared to control group with 
assessment only or printed materials (RR 1.32 for prolonged abstinence and RR 1.14 for point prevalence abstinence). ${ }^{28}$ The main limitation of that review, however, was the focus on smoking cessation among adults, with limited evidence for young smokers.

Most intervention researches to date have been restricted to narrow comparisons of a single eHealth platform among young smokers or adult tobacco users while other vulnerable subgroups such as people living with HIV, hospitalized patients, or opioid-dependent people were not included. Second, previous reviews have shown that combining multiple cessation services and tailoring them to the specific smoker is more effective than a single, broad-based intervention (eg, mHealth and internet-based services). ${ }^{12}$ However, to our knowledge, there has been no comprehensive systematic review comparing direct effects, intervention cost-effectiveness, and potential effect modifiers among published eHealth platform interventions. Third, there is little evidence regarding the level of eHealth penetration on current smoking cessation trajectories. Finally, few studies have examined the effect modifiers that contribute to the prolonged effects of eHealth smoking cessation interventions. Thus, the purpose of this systematic review was to evaluate and compare the effectiveness and identify some potential effect modifiers of the most promising eHealth platforms in smoking cessation contexts including webbased, computer-based, and mobile phone-based programs to help smoking cessation seekers to quit. The effect modifiers were examined in relation to intervention characteristics (eg, tailored/interactive vs untailored/noninteractive), risk of bias, publication date, and study site. This study will extend knowledge of the efficacy and possible effect modifiers based on recent novel evidence and should be beneficial for evidence-based policy and decision making regarding stopsmoking programs.

\section{Method}

\section{Protocol and registration}

A review protocol was registered on the international prospective register of systematic reviews under number CRD42017072560 (https://www.crd.york.ac.uk/PROSPERO/display record.asp?ID $=$ CRD42017072560).

\section{Eligibility and exclusion criteria}

Studies were included based upon the following PICO questions:

(i) Population: current smokers in the general population; (ii) Intervention: eHealth smoking cessation interventions were classified into four groups including:

- Web-based interventions defined by a unique webpage/portal address that could be accessed online.

- Computer-generated programs (alone) were those with a program/application running on PC/laptop foundation. In this method, the program must be downloaded and installed online or offline before using its resources.

- Mobile-based interventions included any apps or text messages (SMS) and other communication via Wireless and mobile phone/cell phone technologies.

- Other platforms: social media (Facebook, Twitter), Chat rooms, digital games, or specific devices aimed at improving smoking abstinence.

Interventions were considered to be "interactive" if information sharing and interaction with the target participants (based on their personal characteristics) were described in the intervention content. Tailored interventions were defined as individually personalized messaging or content delivery to participants.

(iii) Comparison: usual practice or other smoking cessation methods;

(iv) Primary outcomes: levels of smoking abstinence;

(v) Included study designs: randomized controlled trial (RCT), quasi-experimental designs, interrupted time series, and controlled before-after studies.

We excluded studies if they 1) did not meet the inclusion criteria; 2) utilized eHealth methods (e-mail, website, and so on) primarily for data collection or sample recruitment; 3) had short-term follow-up ( $<1$ month); and 4) were smokeless tobacco studies. Additionally, studies that focused on eHealth penetration on recruiting participants or smoking prevention without reporting on quitting smoking behaviors were excluded.

\section{Search strategy}

A systematic search was performed in March 2017 on four electronic databases including MEDLINE, PsycINFO, Embase, and Cochrane Library from inception. Table 1 lists the "text words" searches. We used multiple combinations of search terms and Boolean operators related to smoking, type of device, eHealth, and intervention. The search strategy was modified for each database by experienced experts and researchers. Additionally, reference lists of articles retrieved, and prior relevant systematic reviews were also scanned to determine the additional eligible documents. Table S1 describes the included studies. Open Grey and Google Scholar 
Table I "Textword" searches

\begin{tabular}{|c|c|}
\hline Topic & Key terms \\
\hline Smoking & Tobacco, smok*, cigarette \\
\hline Device & $\begin{array}{l}\text { Mobile phone, smartphone, smart-phone, computer, } \\
\text { tablet, handheld, cellular phone, cell phone }\end{array}$ \\
\hline eHealth & $\begin{array}{l}\text { Online, mobile, technology, electronic health, eHealth, } \\
\text { chat room, social media, mobile application, mobile } \\
\text { health application, mhealth, text messaging, telemedicine, } \\
\text { internet, multimedia, web, electronic mail, e-mail }\end{array}$ \\
\hline Intervention & Intervent*, prevent*, trial, campaign \\
\hline
\end{tabular}

Abbreviations: eHealth, electronic health; mHealth, mobile health.

were searched to find any additional relevant reference, which might not be captured by the selected database searches.

\section{Study selection}

All references were exported to EndNote version X7 and duplicates were removed. Titles and abstracts were independently screened by two authors, HD and LN. The studies that did not meet the eligibility criteria were removed. Full texts of relevant information or those that required further clarifications were retrieved for the final assessment of data collection. A third review author (BT) made a final decision when two reviewers had differing opinions.

\section{Data collection process}

A structured data extraction form was first piloted by two reviewers (HD and LN) and then applied to all studies. Extracted data consisted of 1) description of participants, 2) study design, 3) timing, 4) sample size, 5) length of intervention and follow-up, 6) types of eHealth (web-based, computers, mobile phone-based, quit-line, and so on), 7) primary outcomes, 8) a brief description of experiment, 9) study findings and bias assessment, and 10) effect modifiers (eg, setting, intervention characteristics, year of publication, and risk of bias). Details of the conceptual frameworks were extracted if they were described in sufficient detail. The smoking cessation outcome was also extracted. If the published paper did not provide sufficient information, we searched for its protocol or contacted the authors for further detail.

After completion of the data extraction, the results of the two reviewers (HD and LN) were compared, discussed, and any disagreements were resolved before producing the final data. Senior researchers were consulted to address any disagreements. The meta-analysis was carried out using Review Manager (RevMan) Analyses Ver. 5.3.

The PRISMA (Preferred Reporting Items for Systematic Reviews and Meta-Analyses) guideline was used to describe the flow of the searching and screening. ${ }^{29}$

\section{Data items}

A summary matrix was created with the data extracted from all the included studies. This matrix listed all variables for which data were sought including PICO, length of follow-up, significant behavioral outcomes, theoretical framework, author recommendation, and bias appraisal.

\section{Risk of bias in individual studies}

The included studies were assessed for risk of bias using the Quality Assessment Tool for Quantitative Studies, developed by the Effective Public Health Practice Project (EPHPP). ${ }^{30}$ The EPHPP score ranged from 6 to 24 and global ratings were based on the number of weak ratings (no WEAK rating strong "quality", one WEAK rating - moderate "quality", and more than two WEAK ratings - weak "quality"). Two independent reviewers assessed six potential biases including selection bias, study design, presence or absence of blinding, confounders, data collection bias, and attrition bias. Any disagreements between the two reviewers were discussed together and if necessary with coauthors for verification.

\section{Summary measures}

This review measured the difference in smoking abstinence prevalence by type of eHealth platform, population, and time points. Smoking point prevalence of abstinence at final follow-up (self-assessed abstinence or/with biochemically validated abstinence) was recorded as the primary outcome for treatment effect. Effectiveness was measured by 7-day point abstinence or prolonged abstinence interchangeably because these indicators are strongly related to each other, and it has been shown that the use of either does not affect the results. ${ }^{31}$ Further, we note that 7-day point abstinence prevalence is the most common measure in tobacco cessation intervention studies. Based on recommendations from the literature, we considered abstinence to be short-term if the intervention used was $<6$ months of follow-up, and longerterm abstinence if the intervention reported was $\geq 6$ months of follow-up. ${ }^{32,33}$ The meta-analysis was performed based on the 7-day point prevalence abstinence (PPA) or prolonged abstinence indicator, stratified by follow-up time-points and effect modifier characteristics of the control group (Table 2). To address missing data, withdrawal and dropout cases were considered to be smokers, using results from intention-to-treatanalysis based on Cochrane Tobacco Group's guideline. ${ }^{34}$

\section{Synthesis of results}

$\mathrm{RR}$ and $95 \% \mathrm{CI}$ were used to measure the difference in smoking abstinence prevalence between control and intervention groups 
Table 2 Subgroups of effect modifiers employed in the metaanalysis and meta-regression

\begin{tabular}{|c|c|}
\hline Effect modifiers & Subgroup \\
\hline $\begin{array}{l}\text { Follow-up time- } \\
\text { points }\end{array}$ & $\begin{array}{l}\text { 1. }<6 \text { months of follow-up - short-term abstinence } \\
\text { 2. } \geq 6 \text { months of follow-up - long-term abstinence }\end{array}$ \\
\hline Effective public & I. Weak quality (high risk of bias) \\
\hline health practice & 2. Moderate quality (moderate risk of bias) \\
\hline project ranking & 3. Strong quality (low risk of bias) \\
\hline Target population & $\begin{array}{l}\text { I. Adult smokers } \\
\text { 2. Youths } \\
\text { 3. Other vulnerable subjects (chronic patients, } \\
\text { pregnant women, and so on) }\end{array}$ \\
\hline Tailored & I. Tailored intervention \\
\hline intervention & 2. Untailored intervention \\
\hline Interactive & I. Interactive \\
\hline intervention & 2. Noninteractive \\
\hline Frequency of text & I. High frequency \\
\hline message & 2. Low frequency \\
\hline Control & I. Nonactive control group \\
\hline characteristics & $\begin{array}{l}\text { 2. Active control group } \\
\text { 3. Other eHealth platforms }\end{array}$ \\
\hline Location of trials & $\begin{array}{l}\text { I. Developed countries (USA, EU) } \\
\text { 2. Less developed countries (rest of the world) }\end{array}$ \\
\hline Theory-based & I. Yes \\
\hline intervention & 2. No \\
\hline Clinician contact & $\begin{array}{l}\text { I. Yes } \\
\text { 2. No }\end{array}$ \\
\hline
\end{tabular}

Abbreviation: eHealth, electronic health; EU, European Union.

for each included study. A meta-analysis was conducted using the Mantel-Haenszel fixed-effect approach to pool RRs. The $I^{2}$ statistic was applied to assess the presence of substantial statistical heterogeneity with three cutoff points (LOW $-I^{2}$ $<25 \%$, MODERATE $-I^{2}$ from $25 \%$ to $75 \%$, and HIGH $-I^{2}$ $<75 \%)^{35}$ The visual figure of funnel plots in RevMan5 was employed to assess any potential publication bias and no evidence of publication bias in included studies was found because the included studies distributed symmetrically around the mean. Each primary outcome was Grading of Recommendations Assessment, Development and Evaluation (GRADE) assessed and concluding statements were drawn based on the importance of the evidence to identify what the difference means (eg, may provide an effect [poorer cessation outcome] vs may increase cessation [better cessation outcome]). ${ }^{36}$

To examine further explanations of the high heterogeneity between studies, multi-meta-regression analyses were performed using restricted maximum-likelihood technique. The covariates, which are hypothesized to be effect modifiers, included 1) intervention characteristics (eg, interactive, tailored, frequent, and theory-based intervention); 2) risk of bias (EPHPP); 3) year of publication; and 4) country of study, stratified by three categories of eHealth platforms (ie, webbased, computer-assisted, and mHealth).

\section{Results}

\section{Search outcomes}

Figure 1 shows the flow of studies. Initially, 3,973 potentially relevant records were identified. After deduplication $(\mathrm{n}=239)$ and screening titles and abstract, 3,520 records were excluded. For the remaining 214 records, full-text papers were retrieved and assessed for eligibility. Only 124 papers met the inclusion criteria following further appraisal using the EPHPP tool. An additional 16 studies were excluded due to the focus on smokeless tobacco cessation, ${ }^{37-39}$ school tobacco control program, ${ }^{40-43}$ duplicate publication of study results,,$^{37,44-46}$ and eHealth intervention used for participant recruitment. ${ }^{47-51}$ In total, 108 studies met all selection criteria with 110,372 participants included in the review. High consensus (90\%) was achieved between two reviewers.

\section{Study characteristics}

Table 3 summarizes the main characteristics of the included studies in the review. All but one of the included studies were published in the 21st century (from 2000).

\section{Participants}

Adult smokers were the main target population $(n=64)$, followed by youth $(n=18)$ and other subpopulations with special needs such as people living with HIV, COPD, or pregnant women. Most of the studies were implemented in the USA ( $\mathrm{n}=58)$, Europe $(\mathrm{n}=41)$, and Asia and Australia regions $(\mathrm{n}=9)$. No studies were found in Africa.

\section{eHealth interventions}

This review captured 67 studies that used web-based programs, followed by wireless and mobile phone-based programs $(n=24)$, and computer-assisted intervention $(n=13)$. Social media, virtual chat room, or other electronic aids were investigated in four studies only.

\section{Comparison}

The included studies were dominated by two arms $(\mathrm{n}=82)$, following by three arms $(n=20)$, four arms $(n=4)$, and five arms $(n=2)$. eHealth smoking cessation interventions were compared to nonactive control groups including usual care, self-help materials, assessment only ( $\mathrm{n}=63$ ); active control groups (eg, quit-line, face-to-face counseling) $(n=13)$, and other types of eHealth interventions $(\mathrm{n}=30)$. Only two studies, the improvement of sleep or physical activity, were compared with non-smoking-cessation groups. 


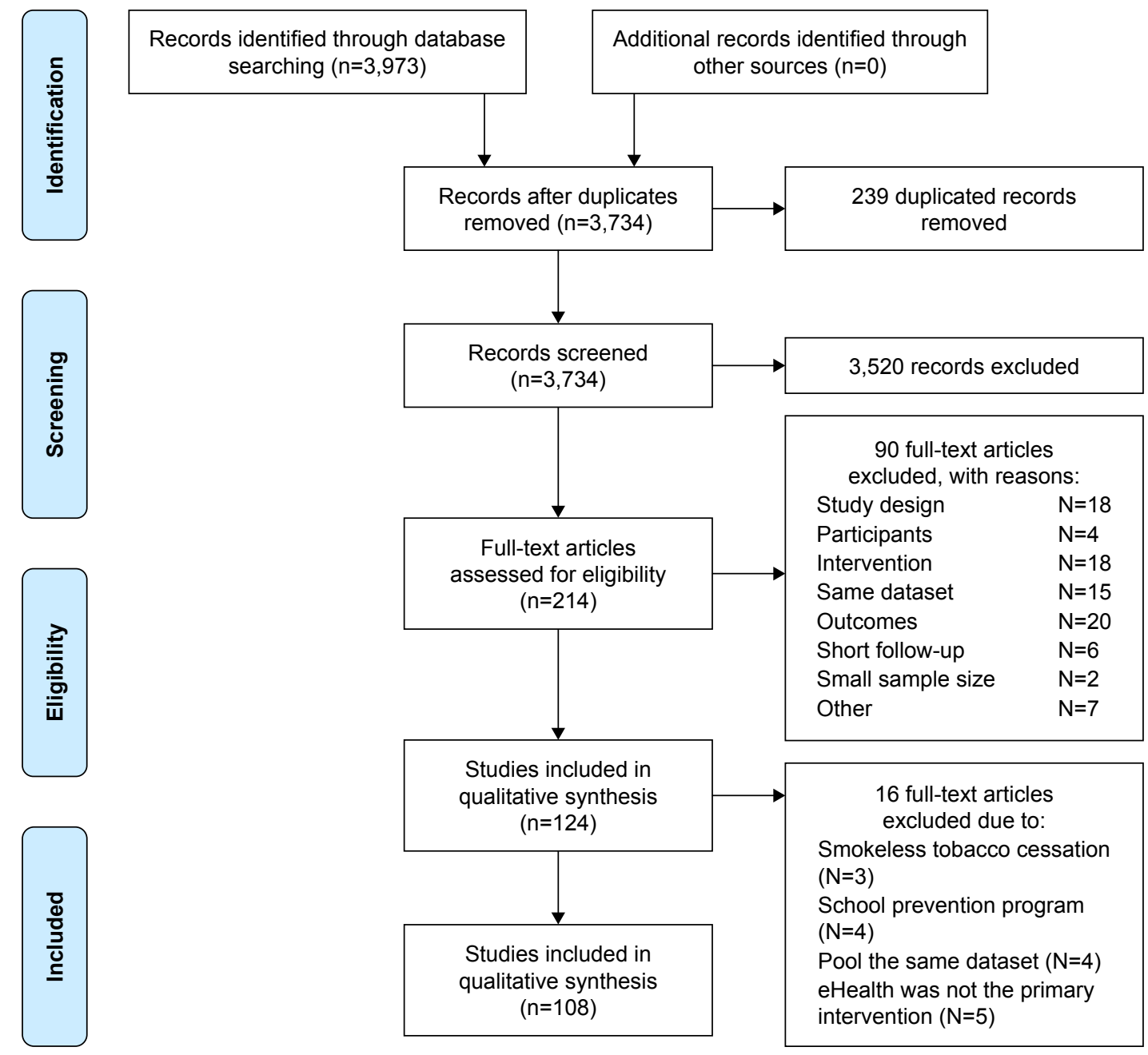

Figure I PRISMA diagram of searching and screening process.

Abbreviation: eHealth, electronic health; PRISMA, Preferred Reporting Items for Systematic Reviews and Meta-Analyses.

\section{Outcome}

Most of the studies measured abstinence from 6 to 12 months of follow-up ( $\mathrm{n}=48)$, and some measured longer follow-up at more than 12 months $(n=28)$. The remaining studies $(n=32)$ measured short-term outcomes (from 1 to less than 6 months).

\section{Risk of bias within studies}

Figure 2 provides the risk of bias appraisal by individual studies, using the EPHPP tool. The average quality score among 108 included studies was 8.5 (described in Table S1). Attrition bias for noncompliance (less than 60\%) was the major bias, accounting for $27 \%$ among 30 studies. Meanwhile, high risk of inadequate blinding was found in 22 studies due to the fact that participants were aware of treatment allocation while blinding of assessors was not reported clearly. Selection bias might have occurred in 18 studies since $<60 \%$ of recruited respondents agreed to participate in the intervention. Data collection method was rated unclear/ moderate bias in 27 studies due to self-reported assessment without biochemical confirmation of smoking abstinence. Overall, $18 \%$ of included studies $(n=17)$ were deemed to be of weak quality (with two weak points). In contrast, the remaining part was of moderate and strong quality (41\% vs $39 \%$, respectively).

\section{Effectiveness of internet smoking cessation interventions \\ Web-based compared to nonactive control}

The forest plot (Figure 3) shows a positive effect of webbased smoking cessation interventions compared to control groups. Twenty web-based trials reported higher abstinence prevalence compared to participants in the nonactive control groups who received minimal or no intervention, such as assessment only or printed materials for adult smokers, ${ }^{52-69}$ youth, ${ }^{70-78}$ and other smokers with special needs such as pregnant women, ${ }^{79}$ people with COPD,${ }^{80}$ heart disease, ${ }^{81}$ cancer, ${ }^{82}$ or HIV/AIDS. ${ }^{83,84}$ When 23 studies about the 
Table 3 General characteristics of included studies $(n=91)$

Characteristics

Publication year

- 2010 to Feb 2017

- 2000-2009

- 1999

Study designs

- Randomized control trial

- Quasi-experiment

- Controlled before-after studies

Intervention

- Web-based

- Computer-based

- mHealth (SMS, apps)

- Others (social media, chat-room, and other electronic aids)

Settings

- USA

- Europe

- Australia and New Zealand

- Asia

Participants

- Adults

- Youth (from 15 to 24 years old)

- Patients with chronic disease, pregnant women

Multiple eHealth platforms

- Single eHealth platform

- Multiple eHealth platforms

- Combined with non-eHealth platform

- Combined with financial incentives

Theoretical framework

- Transtheoretical model

- Cognitive-behavioral therapy

- Social cognitive theory

- Multitheories

- Not available

- Others

Method to confirm smoking status

- Self-report

- Biochemically validation (CO breath test or urine test)

Length of follow-up

- From I to $<6$ months

- From 6 to 12 months

- More than 12 months

Abbreviations: $\mathrm{CO}$, exhaled carbon monoxide; eHealth, electronic health; mHealth, mobile health.

prevalence of smoking abstinence were pooled together, the interactive, tailored, and web-based programs demonstrated increased cessation effects for 6-month follow-up interventions (RR 2.03, 95\% CI 1.73-2.38), $I^{2}=27 \%$, and a moderate increase of smoking cessation in 11 studies with less than 6 months of follow-up (RR 1.21, 95\% CI 1.08-1.36, $I^{2}=20 \%$ ). In contrast, no meaningful effect on quitting cigarettes was found after pooling eleven internet studies at 12 months of follow-up (RR 1.06, 95\% CI 0.98-1.16, $I^{2}=47 \%$ ).
Interactive tailored web-based compared to an active control group

Five of 18 studies found significant long-term effects of the tailored proactive web-based interventions compared to active control activities such as a brief generic text advice, ${ }^{85}$ a noninteractive, nontailored internet, ${ }^{86}$ and a state-of-theart tailored web-based tobacco interventions. ${ }^{87}$ Two studies detected a short-term effect at both 1 and 3 months when measuring the effect of the proactive website (Opptur/www. slutta.no $)^{88}$ or a video-validated abstinence via financial incentives based on the Mōtiv8 website. ${ }^{89}$ Compared to an active control group, the web-based program tailored to participants' characteristics indicated little or no increase of cessation effect (RR 1.09, 95\% CI 1.02-1.17, $I^{2}=0 \%$ ).

\section{Web-based compared to other eHealth control groups}

Eight studies compared the effects of online smoking cessation programs with other eHealth modes for adult smokers. ${ }^{85,90-96}$ Fraser $\left.(2014)\right)^{90}$ concluded that website information without e-mail messaging had significantly increased smoking abstinence because messaging may undermine website utilization. ${ }^{90}$ McKay (2008) measured the abstinence difference between a website using a cognitive-behavioral therapy approach and a control group receiving physical activity advice, but no significant difference was detected at either 3 or 6 months of follow-up..$^{91}$ Other RCTs compared the effects of interactive smoking cessation websites and multiple types of methods such as e-mail reminders or virtual groups, ${ }^{93,94}$ video messages vs SMS advice, ${ }^{85,95}$ and proactive telephone counseling. ${ }^{96}$ It was concluded that participants who used the video-based website were more likely to be abstinent than people receiving tailored feedback via plain SMS. Meanwhile, Swan (2010) indicated that compared to web-based counseling, proactive telephone-based counseling has a significant short-term effect at 3 months, but no substantial benefit at 6 months. ${ }^{96}$ When putting together the smoking abstinence prevalence from eight RCTs, web-based interventions had no additional effect on 7-day abstinence prevalence compared to other eHealth platforms (e-mail, video, and chat room) with RR $1.03,95 \%$ CI $0.94-1.13, P=0.55$. Statistical heterogeneity was moderate $\left(I^{2}=37 \%\right)$.

\section{Web-based integrated with pharmacotherapy}

Results from 11 studies offered nicotine replacement therapy (NRT) via webpage showed moderate effect (RR 1.29, 95\% CI 1.17-1.43, $P<0.001)$. Based on the GRADE guideline, these interventions probably increase cessation 


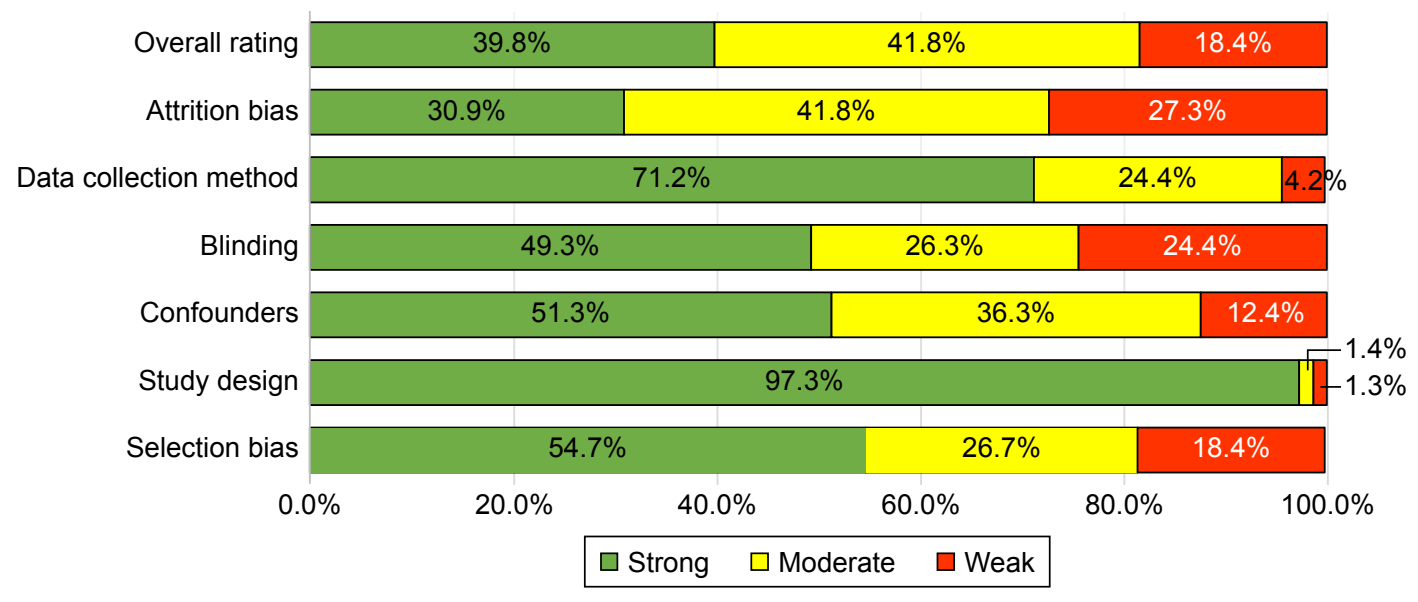

Figure 2 Risk of bias graph based on review authors' judgments across all included studies.

slightly due to statistical heterogeneity $\left(I^{2}=42 \%, P<0.001\right)$. Of the 11 studies, six had pharmacotherapy components that were associated with significant improvement in abstinence in webpage interventions vs control conditions. Brendyen (2008) emphasized that SMS and webpages with both e-mail and interactive voice response improved treatment outcomes (eg, repeated point abstinence, NRT adherence, and self-efficacy) compared to those who received only self-help material and NRT. ${ }^{53}$ Meanwhile, there was greater evidence of effectiveness when a tobacco tactics website was combined with nurse counseling via phone and NRT, when compared with eHealth smoking cessation intervention without human contact (eg, quit-line group, ${ }^{97}$ nicotine mini-lozenges supported by a website, ${ }^{90}$ a smoke-free"website for people living with HIV/AIDS, ${ }^{98}$ e-treatment software with mobile text messages, ${ }^{99}$ webbased smoking-cessation with tailored achievement stories $^{100}$ ). In contrast, some RCTs were unable to show substantial effects of webpage smoking treatment plus NRT for HIV-positive smokers. ${ }^{101-103}$ Similarly, no significant treatment difference was detected in the internet-homebased program for adolescents compared to a clinic-based, individual counseling. ${ }^{104}$

\section{Effectiveness of mHealth smoking cessation intervention}

Mobile-based smoking cessation programs were conducted in eight studies for adult smokers, ${ }^{7-11,105-107}$ nine studies for young smokers, ${ }^{108-116}$ and five interventions (seven reports) for HIV-positive patients or pregnant smokers. ${ }^{117-123}$ Among 22 mHealth interventions, the significant effect on smoking abstinence was confirmed in five studies among adults, $,{ }^{7,9}, 105-107$ six studies among young smokers, ${ }^{109,111-114,116}$ and three smoking interventions for pregnant woman and HIV-positive patients. ${ }^{118,119,123}$ However, due to high heterogeneity $\left(I^{2}>81 \%\right)$, the effect of the study sample was not pooled by the meta-analysis.

Regarding mobile apps, only three studies examined the impact of mobile apps on improving smoking cessation. However, due to methodologic weaknesses, such as small sample size (eleven participants), ${ }^{124}$ no control group and short-term follow-up (1 week), ${ }^{125,126}$ three studies were excluded in the review. Figure 4 demonstrates the benefits of mobile-based smoking cessation intervention compared with various types of control groups.

\section{mHealth interventions vs nonactive controls}

Text messaging-supported cessation interventions were examined in eight studies, with comparisons to nonactive controls who received usual care or a quitting brochure only. Seven studies did not detect statistically significant differences between the conditions, ${ }^{10,11,114,118,119}$ even where there were fully automated tailored SMS, ${ }^{111}$ or mobile phone-delivered counseling combined with varenicline. ${ }^{121}$ Ferguson found that the text messages may support improved use of pharmacotherapy. It is also possible that the reverse is also true if medications promote the beneficial effects of a behavioral strategy. ${ }^{10}$ A statistically significant benefit of proactive counseling phone calls was detected by Vidrine (2015) in an effort to improve smoking abstinence through changing self-efficacy among HIV-positive patients. ${ }^{123}$ After including eight text messaging studies in the metaanalysis, the RR illustrated an important increase of cessation effect of text-messaging and cell-phone intervention, compared to nonactive control group (RR 1.71, 95\% CI $1.35-2.16, I^{2}=5 \%$ ). 


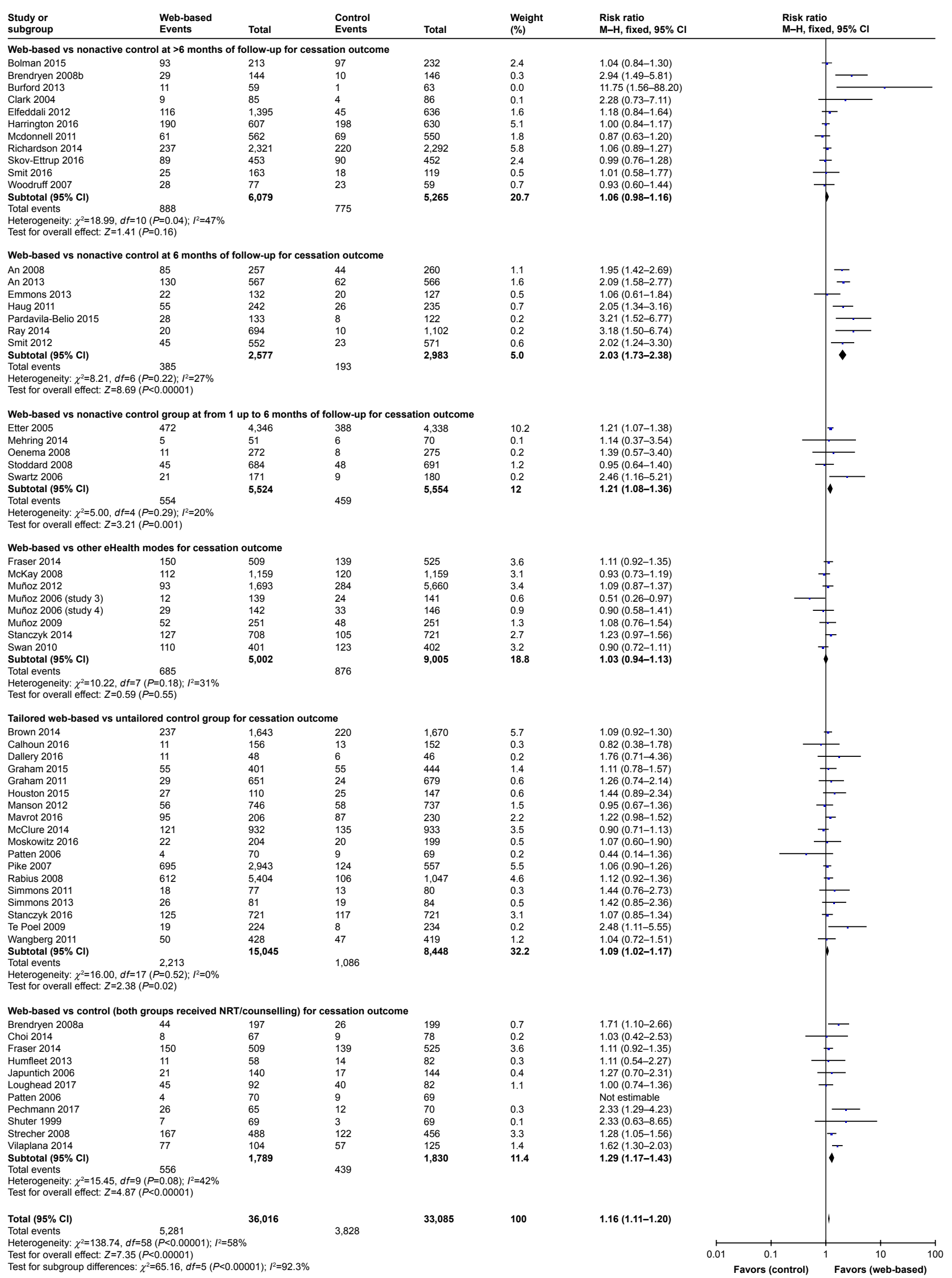

Figure 3 Forest plot of web based intervention effects by characteristics of control group.

Abbreviations: $\mathrm{M}-\mathrm{H}$, Mantel-Haenszel; NRT, nicotine replacement therapy. 


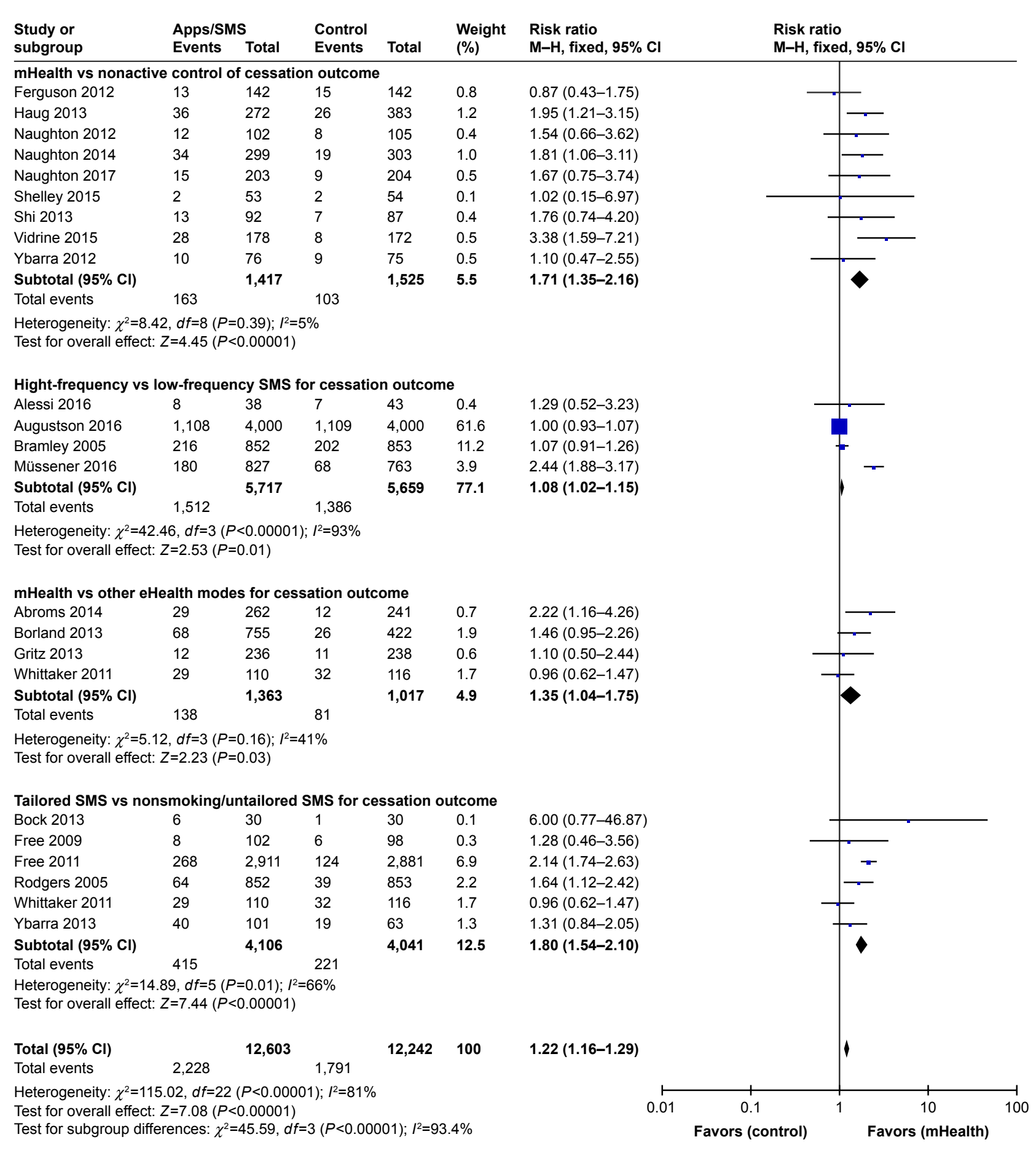

Figure 4 Forest plot of mHealth intervention effects by characteristics of control group. Abbreviations: eHealth, electronic health; $\mathrm{M}-\mathrm{H}$, Mantel-Haenszel; mHealth, mobile health.

High-frequency SMS vs low-frequency control group

Four studies compared effects on smoking abstinence between text-message conditions (multiple SMS intervention vs single SMS per week) to explore the impact of SMS intensity on behavior change. Augustson (2016) developed an intervention that delivered smoking cessation advice via three messages daily, compared to the control group that received once-weekly SMS containing smoking health effects information only. ${ }^{8}$ Bramley (2005) utilized personalized SMS daily vs SMS monthly among the Maori population in New Zealand. ${ }^{108}$ Müssener (2016) designed a 12-week NEXit core program, which had 157 text messages compared to one text per 2 weeks in the control group. Only the NEXit core program detected a short-term effect of the 
intervention, whereas no significant effects were found in the other studies. An mHealth application used a camera phone to prompt participants to conduct exhaled carbon monoxide tests, in combination with a brief advice via mobile phone and transdermal nicotine. Participants in the intervention group received a prize for a negative exhaled carbon monoxide test outcome. ${ }^{105}$ However, no significant effect was found at 6 months of follow-up (OR $=0.99,95 \%$ CI $0.98-1.01)$. Due to high heterogeneity $\left(I^{2}=93 \%\right)$, the meta-analysis was not employed to pool the effects of these trials.

\section{mHealth vs other eHealth platforms (webpage/social media/computer-based program)}

Four studies evaluated the text messages program compared to website or computer-supported program. Abroms (2014) developed a Text2Quit program delivering automated, interactive text messages based on social cognitive theory with the supports of e-mails and a website, compared to a smoking cessation website (Smokefree.gov). This trial revealed a strong effect of the intervention with $\mathrm{RR}=2.22$ (95\% CI 1.16-4.26). ${ }^{7}$ Similarly, a 3-month mobile phonebased counseling intervention plus hotline for people living with HIV, compared with an audio computer-supported selfinterview and quit advice in the USA, found that the treatment effect was maximized at 3 months $(\mathrm{OR}=4.3, P<0.001)$ and decline to $2.41(P=0.49)$ at 6 and 12 months. ${ }^{117}$ In contrast, no significant difference was found between a text messaging program (onQ), which provided a daily SMS tailored to the participant's progress toward quitting, vs a static website in Australia. ${ }^{106,127}$ After pooling, the mHealth effect was confirmed with $\mathrm{RR}=1.35,95 \%$ CI $1.04-1.75$. This group of three studies had no observable heterogeneity $\left(I^{2}=0 \%\right)$. This result suggested that the mHealth intervention via text messaging may increase cessation slightly compared to a website-only intervention.

\section{Tailored SMS vs untailored SMS}

Six studies compared the tailored SMS to general SMS. Three mHealth studies applied a text messaging quitting program called txt2stop that included motivational SMS and behavioral change encouragement plus a $£ 20$ prepaid voucher, while the control group received a general SMS on other health topics. Rodgers (2005) initiated a trial in New Zealand and Free (2005) piloted and adapted the trial for young smokers $(>16$ years) in the UK, along with a quit buddy and SMS regarding craving, before conducting a full trial in 2011. Roger (2005) found that the quit rate at 26-week follow-up was statistically greater in the intervention $(7.5 \%)$ compared to the control group (4.6\%), RR =1.64 (95\% CI 1.12-2.42). ${ }^{113}$ The study by Free (2001) among 200 smokers found a short-term effect of smoking abstinence at 4-week follow up $(\mathrm{R}=2.08)$ but not a statistically significant difference at 6 months of follow-up $(\mathrm{RR}=1.28) .{ }^{109}$ When the full trial was carried out among 5,800 smokers, participants in the intervention group received personalized SMS advice while the control group was delivered one untailored SMS/2 weeks. That study found a 6-month sustained benefit of the intervention on 7-day PPA and continuous abstinence ( $\mathrm{RR}=1.32,95 \% \mathrm{CI} 1.19-1.47) .{ }^{110}$

Further evidence of a substantial effect of tailored text messages (based on quit stage) compared to text messages unrelated to smoking cessation in a control group was found in a trial conducted by Bock et al. ${ }^{9}$ When integrated with a video, the tailored text messages were not significantly beneficial to smokers after 6 months of follow-up, compared to a control group that received general health multimedia messages. ${ }^{115}$ A short-term improvement in smoking abstinence at 4 weeks of follow-up was found in a 6-week messaging program in the USA (OR 3.33, 95\% CI 1.48-7.45) but when measured at 3 months, the effect was not statistically significant. ${ }^{116}$ The pooled effect of six studies demonstrated that tailored SMS may increase cessation $(\mathrm{RR}=1.8$, 95\% CI 1.54-2.1), but this result should be interpreted with caution due to significantly moderate heterogeneity among studies $\left(I^{2}=66 \%, P=0.01\right)$.

\section{Effectiveness of computer-assisted smoking cessation intervention}

Figure 5 illustrates that nine computer-assisted studies were conducted among adult smokers ${ }^{128-136}$ while only four studies were undertaken among young smokers $(n=2),{ }^{137,138}$ HIV patients, and pregnant women $(n=2) .{ }^{139,140}$ Among adult smokers, six studies showed improved smoking abstinence. ${ }^{129-133,135}$ The pooled effect of nine intervention resulted in greater smoking abstinence prevalence compared to control groups $(\mathrm{RR}=1.19,95 \%$ CI 1.09-1.29, $P<0.001)$ and low heterogeneity $\left(I^{2}=0 \%\right)$. Similar results were found after pooling effects of two studies targeting patients (eg, HIV-positive patients, chronic patients) and pregnant women $(\mathrm{RR}=1.66,95 \%$ CI 1.06-2.62, $P=0.03$, $\left.I^{2}=0 \%\right)$. In contrast, two computer-based interventions among young smokers did not yield a statistically significant effect $\left(\mathrm{RR}=1.39,95 \%\right.$ CI $\left.0.88-2.19, P=0.15, I^{2}=0 \%\right)$.

Among six studies using computer-assisted smoking cessation interventions compared to nonactive control groups, ${ }^{129,131,133,134,136,141}$ only two studies using individualized and interactive expert system computer reports, ${ }^{132}$ and 


\begin{tabular}{|c|c|c|c|c|c|c|}
\hline $\begin{array}{l}\text { Study or } \\
\text { Subgroup }\end{array}$ & $\begin{array}{l}\text { Compute } \\
\text { Events }\end{array}$ & $\begin{array}{l}\text { r-based } \\
\text { Total }\end{array}$ & $\begin{array}{l}\text { Control } \\
\text { Events }\end{array}$ & Total & $\begin{array}{l}\text { Weight } \\
(\%)\end{array}$ & $\begin{array}{l}\text { Risk ratio } \\
\text { M-H, fixed, } 95 \%\end{array}$ \\
\hline \multicolumn{7}{|c|}{ Computer-based vs usual care, assessment only for cessation outcome } \\
\hline Bolman 2015 & 93 & 213 & 97 & 232 & 9.4 & $1.04(0.84-1.30)$ \\
\hline Borland 2004 & 103 & 521 & 112 & 537 & 11.2 & $0.95(0.75-1.20)$ \\
\hline Hoving 2010 & 33 & 256 & 28 & 289 & 2.7 & $1.33(0.83-2.14)$ \\
\hline Meyer 2016 & 47 & 534 & 27 & 388 & 3.2 & $1.26(0.80-1.99)$ \\
\hline Prochaska 2001b & 338 & 1,358 & 554 & 2,786 & 36.9 & $1.25(1.11-1.41)$ \\
\hline Riley 2002 & 6 & 49 & 3 & 44 & 0.3 & $1.80(0.48-6.76)$ \\
\hline Schumann 2008 & 69 & 424 & 68 & 423 & 6.9 & $1.01(0.74-1.38)$ \\
\hline Unrod 2007 & 28 & 237 & 18 & 228 & 1.9 & $1.50(0.85-2.63)$ \\
\hline Wetter 2011 & 39 & 151 & 40 & 151 & 4.1 & $0.97(0.67-1.42)$ \\
\hline Subtotal $(95 \% \mathrm{Cl})$ & & 3,743 & & 5,078 & 76.5 & $1.16(1.06-1.26)$ \\
\hline Total events & 756 & & 947 & & & \\
\hline \multicolumn{7}{|c|}{ Heterogeneity: $\chi^{2}=8.45, d f=8(P=0.39) ; l^{2}=5 \%$} \\
\hline \multicolumn{7}{|c|}{ Test for overall effect: $Z=3.37(P=0.0008)$} \\
\hline \multicolumn{7}{|c|}{ Computer-based vs active control for cessation outcome } \\
\hline Lawrence 2005 & 20 & 324 & 9 & 289 & 1.0 & $1.98(0.92-4.28)$ \\
\hline Meyer 2012 & 155 & 1,484 & 48 & 618 & 6.9 & $1.34(0.99-1.83)$ \\
\hline O'Neill 2000 & 10 & 31 & 10 & 34 & 1.0 & $1.10(0.53-2.27)$ \\
\hline Prokhorov 2008 & 25 & 158 & 17 & 168 & 1.7 & $1.56(0.88-2.78)$ \\
\hline Sutton 2007 & 158 & 765 & 126 & 743 & 13.0 & $1.22(0.99-1.50)$ \\
\hline Subtotal $(95 \% \mathrm{Cl})$ & & 2,762 & & 1,852 & 23.5 & $1.31(1.11-1.53)$ \\
\hline Total events & 368 & & 210 & & & \\
\hline \multicolumn{7}{|c|}{ Heterogeneity: $\chi^{2}=2.18, d f=4(P=0.70) ; l^{2}=0 \%$} \\
\hline \multicolumn{7}{|c|}{ Test for overall effect: $Z=3.28(P=0.001)$} \\
\hline Total $(95 \% \mathrm{Cl})$ & & 6,505 & & 6,930 & 100 & $1.19(1.11-1.28)$ \\
\hline Total events & 1,124 & & 1,157 & & & \\
\hline \multicolumn{7}{|c|}{ Heterogeneity: $\chi^{2}=12.27, d f=13(P=0.51) ; I^{2}=0 \%$} \\
\hline \multicolumn{7}{|c|}{ Test for overall effect: $Z=4.59(P<0.00001)$} \\
\hline Test for subgroup & ences: $\chi$ & $c^{2}=$ & & & & \\
\hline
\end{tabular}

Figure $\mathbf{5}$ Forest plot of computer-assisted intervention effects by characteristics of control group. Abbreviation: $\mathrm{M}-\mathrm{H}$, Mantel-Haenszel.

tailored computer-generated advice reports sent to smokers at strategically suitable times found greater 6-month treatment outcomes compared to control conditions. ${ }^{128,132}$ The pooled effect of eight studies revealed little or no increase of cessation (RR=1.16, 95\% CI 1.06-1.26, $P=0.0007, I^{2}=7 \%$ ). The stronger efficacy of computer-assisted intervention was demonstrated in the pooled effect of five studies ${ }^{130,135,137-139}$ ( $\mathrm{RR}=1.31,95 \%$ CI $1.11-1.53, P=0.001, I^{2}=0 \%$ ). However, all five individual studies did not find statistically significant difference between a computer-assisted program and active control groups receiving brief counseling, ${ }^{130,138}$ or self-help material, ${ }^{139}$ or telephone counseling. ${ }^{135}$ The total effect of computer-generated technology was pooled, and based on the results of 14 studies, the magnitude of effect was $R R=1.21$ (95\% CI 1.11-1.31) with low heterogeneity $\left(I^{2}=0 \%\right)$.

\section{Effectiveness of other eHealth intervention}

The efficacy of integrated video features was investigated in three studies using a "video doctor" for pregnant women, ${ }^{141}$ a tailored video-based website, ${ }^{66}$ and video messages for adults. ${ }^{85}$ Due to the high heterogeneity of studies $\left(I^{2}=76 \%\right)$, the effect of the varieties of eHealth technology was not pooled via meta-analysis. Table 4 summarizes the effect magnitude of the three eHealth interventions, subgrouped by different comparison groups.

\section{Core effect modifiers}

Results from meta-regression in Table 5 show heterogeneity and identify sources of effect modifiers in the meta-analysis. The $\log \mathrm{RR}$ was estimated to decrease by 0.146 per unit increase in the EPHPP ranking. In other words, studies that have high risk of bias are more likely to overestimate the effect of web-based smoking cessation interventions. On the other hand, for mobile-based smoking cessation, the treatment effect is moderated by the trial characteristics (eg, tailored content, frequent SMS) and country where the trial was conducted. Interestingly, the $\log \mathrm{RR}$ was estimated to increase by 0.45 and decrease by 0.224 when quitting SMS was tailored to participants' characteristics and daily SMS delivery, compared to untailored and weekly SMS, respectively.

\section{Discussion}

This systematic review examined the efficacy of four eHealth behavioral interventions (internet-based, 
Table 4 Summary of findings on effects of eHealth smoking cessation interventions, based on GRADE guidelines

\begin{tabular}{|c|c|c|c|c|}
\hline $\begin{array}{l}\text { Outcome, } \\
\text { follow-up }\end{array}$ & $\begin{array}{l}\text { Summary of the } \\
\text { effect }(95 \% \mathrm{CI})\end{array}$ & $\begin{array}{l}\text { Number of } \\
\text { participants } \\
\text { and studies }\end{array}$ & $\begin{array}{l}\text { Quality of } \\
\text { the evidence } \\
\text { (GRADE) }\end{array}$ & $\begin{array}{l}\text { Summary for } \\
\text { intervention }\end{array}$ \\
\hline \multicolumn{5}{|c|}{ Web-based smoking cessation interventions } \\
\hline \multicolumn{5}{|c|}{ Web-based vs nonactive control } \\
\hline Cessation, $>6$ months & $\begin{array}{l}\text { RR I.06 (0.99-1.16) } \\
\text { Little or no increase }\end{array}$ & $\begin{array}{l}\text { II,344; } \\
\text { II studies }\end{array}$ & $\begin{array}{l}\oplus \oplus \oplus \ominus^{\mathrm{a}} \\
\text { Moderate }\end{array}$ & $\begin{array}{l}\text { Probably little or no } \\
\text { increase upon cessation }\end{array}$ \\
\hline Cessation, 6 months & $\begin{array}{l}\text { RR } 2.03 \text { (I.7-2.03) } \\
\text { Important increase }\end{array}$ & $\begin{array}{l}5,560 \\
7 \text { studies }\end{array}$ & $\begin{array}{l}\oplus \oplus \ominus \ominus^{b} \\
\text { Low }\end{array}$ & May increase cessation \\
\hline Cessation, I-6 months & $\begin{array}{l}\text { RR I.2I (1.08-I.36) } \\
\text { Moderate increase }\end{array}$ & $\begin{array}{l}\text { II,078; } \\
5 \text { studies }\end{array}$ & $\begin{array}{l}\oplus \oplus \oplus \ominus^{\mathrm{a}} \\
\text { Moderate }\end{array}$ & $\begin{array}{l}\text { Probably increases } \\
\text { cessation slightly }\end{array}$ \\
\hline \multicolumn{5}{|c|}{ Tailored web-based vs untailored control group } \\
\hline Cessation, any follow-up & $\begin{array}{l}1.09(1.02-1.17) \\
\text { Little or no increase }\end{array}$ & $\begin{array}{l}23,493 \\
\text { I8 studies }\end{array}$ & $\begin{array}{l}\oplus \oplus \oplus \ominus^{\mathrm{a}} \\
\text { Moderate }\end{array}$ & $\begin{array}{l}\text { Probably little or no } \\
\text { increase upon cessation }\end{array}$ \\
\hline \multicolumn{5}{|c|}{ Web-based vs control group, both groups received NRT/counseling } \\
\hline Cessation, any follow-up & $\begin{array}{l}1.29(1.17-1.43) \\
\text { Moderate increase }\end{array}$ & $\begin{array}{l}3,619 ; \\
\text { II studies }\end{array}$ & $\begin{array}{l}\oplus \oplus \oplus \ominus^{\mathrm{a}} \\
\text { Moderate }\end{array}$ & $\begin{array}{l}\text { Probably increases } \\
\text { cessation slightly }\end{array}$ \\
\hline \multicolumn{5}{|c|}{ Web-based vs other eHealth modes for cessation outcome } \\
\hline Cessation, any follow-up & $\begin{array}{l}\text { I.03 }(0.94-1.13) \\
\text { Little or no increase }\end{array}$ & $\begin{array}{l}\text { I5,568; } \\
8 \text { studies }\end{array}$ & $\begin{array}{l}\oplus \oplus \oplus \ominus^{\mathrm{a}} \\
\text { Moderate }\end{array}$ & $\begin{array}{l}\text { Probably little or no } \\
\text { increase upon cessation }\end{array}$ \\
\hline \multicolumn{5}{|c|}{ mHealth smoking cessation interventions } \\
\hline \multicolumn{5}{|l|}{ mHealth vs nonactive control } \\
\hline Cessation, any follow-up & $\begin{array}{l}\text { I.7I (1.35-2.16) } \\
\text { Important increase }\end{array}$ & $\begin{array}{l}2,942 ; \\
9 \text { studies }\end{array}$ & $\begin{array}{l}\oplus \oplus \ominus \ominus^{\mathrm{b}} \\
\text { Low }\end{array}$ & May increase cessation \\
\hline \multicolumn{5}{|c|}{ High-frequency vs low-frequency SMS } \\
\hline Cessation, any follow-up & $\begin{array}{l}1.08(1.02-1.15) \\
\text { Little or no increase }\end{array}$ & $\begin{array}{l}\text { II,376; } \\
4 \text { studies }\end{array}$ & $\begin{array}{l}\oplus \oplus \ominus \ominus^{\mathrm{a}, \mathrm{c}} \\
\text { Low }\end{array}$ & $\begin{array}{l}\text { May make little or no } \\
\text { difference upon cessation }\end{array}$ \\
\hline \multicolumn{5}{|c|}{ mHealth vs other eHealth modes } \\
\hline Cessation, any follow-up & $\begin{array}{l}1.35(1.04-1.75) \\
\text { Moderate increase }\end{array}$ & $\begin{array}{l}2,389 ; \\
4 \text { studies }\end{array}$ & $\begin{array}{l}\oplus \oplus \ominus \ominus^{\mathrm{a}, \mathrm{d}} \\
\text { Low }\end{array}$ & $\begin{array}{l}\text { May increase cessation } \\
\text { slightly }\end{array}$ \\
\hline \multicolumn{5}{|c|}{ Tailored SMS vs nonsmoking/untailored SMS } \\
\hline Cessation, any follow-up & $\begin{array}{l}\text { I.80 (1.54-2.10) } \\
\text { Important increase }\end{array}$ & $\begin{array}{l}8,147 \\
6 \text { studies }\end{array}$ & $\begin{array}{l}\oplus \oplus \ominus \ominus^{\mathrm{a}, \mathrm{c}} \\
\text { Low }\end{array}$ & May increase cessation \\
\hline \multicolumn{5}{|c|}{ Computer-assisted smoking cessation intervention } \\
\hline \multicolumn{5}{|l|}{ Computer-based vs usual care } \\
\hline Cessation, any follow-up & $\begin{array}{l}\text { 1.16 (1.06-1.26) } \\
\text { Little or no increase }\end{array}$ & $\begin{array}{l}\text { I,703; } \\
9 \text { studies }\end{array}$ & $\begin{array}{l}\oplus \oplus \ominus \ominus^{b} \\
\text { Low }\end{array}$ & $\begin{array}{l}\text { May make little or no } \\
\text { increase upon cessation }\end{array}$ \\
\hline \multicolumn{5}{|c|}{ Computer-based vs active control } \\
\hline Cessation, any follow-up & $\begin{array}{l}\text { I.31 }(1.11-1.53) \\
\text { Moderate increase }\end{array}$ & $\begin{array}{l}\text { 13,435; } \\
5 \text { studies }\end{array}$ & $\begin{array}{l}\oplus \oplus \ominus \ominus^{\mathrm{b}} \\
\text { Low }\end{array}$ & $\begin{array}{l}\text { May increase cessation } \\
\text { slightly }\end{array}$ \\
\hline
\end{tabular}

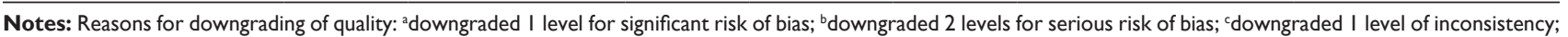
ddowngraded I level for imprecision. GRADE Working Group grades of evidence. $\oplus \oplus \oplus \oplus$ High quality: Further research is very unlikely to change our confidence in the estimate of effect. $\oplus \oplus \oplus \ominus$ Moderate quality: Further research is likely to have an important impact on our confidence in the estimate of effect and may change the estimate. $\oplus \oplus \ominus \ominus$ Low quality: Further research is very likely to have an important impact on our confidence in the estimate of effect and is likely to change the estimate.

Abbreviations: eHealth, electronic health; GRADE, Grading of Recommendations Assessment, Development and Evaluation; mHealth, mobile health; NRT, nicotine replacement therapy; RR, risk ratio.

mobile-based, computer-assisted, and other electronic aids) in helping people to quit smoking. Unfortunately, most of the evidence for beneficial effects is limited to follow-up at 6 months or less, with few demonstrations of longer-term abstinence. This review also explored specific attributes of eHealth and other interventions that can contribute to successful smoking abstinence. Most of the studies were conducted in affluent countries such as the USA, Canada, Europe, Australia, China, and Japan where communications technology has been widely available over several decades. There is a lack of evidence from middle- and low-income countries in Asia and Africa, where there is limited access to coordinated eHealth efforts. Future eHealth smoking cessation interventions should be conducted in developing countries, focus on disadvantaged groups, and measure long-term outcomes for a more comprehensive evaluation of the effectiveness of technology-based interventions. 
Table 5 Core effect modifier using meta-regression, stratified by eHealth platforms

\begin{tabular}{|c|c|c|}
\hline Covariates & $\begin{array}{l}\text { Treatment effect } \\
\text { Log RR }(95 \% \mathrm{Cl})\end{array}$ & $P$-value \\
\hline \multicolumn{3}{|l|}{ Web-based $(n=58)$} \\
\hline EPHPP ranking (weak-moderate-strong) & $-0.146(-0.250$ to $-0.04 I)$ & 0.006 \\
\hline Interactive intervention (yes vs no) & $0.030(-0.120$ to 0.179$)$ & 0.696 \\
\hline Tailored intervention (yes vs no) & $-0.087(-0.239$ to 0.064$)$ & 0.259 \\
\hline Theory-based intervention (yes vs no) & $-0.106(-0.266$ to 0.054$)$ & 0.196 \\
\hline \multicolumn{3}{|l|}{ Computer-assisted $(n=14)$} \\
\hline EPHPP ranking (weak-moderate-strong) & $0.074(-0.101$ to 0.248$)$ & 0.407 \\
\hline Interactive intervention (yes vs no) & $0.119(-0.047$ to 0.285$)$ & 0.16 \\
\hline Tailored intervention (yes vs no) & $0.160(-0.095$ to 0.416$)$ & 0.219 \\
\hline Theory-based intervention (yes vs no) & $-0.244(-0.865$ to 0.376$)$ & 0.440 \\
\hline Clinician contact (yes vs no) & $0.086(-0.169$ to -0.341$)$ & 0.509 \\
\hline \multicolumn{3}{|l|}{ mHealth $(n=2 I)$} \\
\hline EPHPP ranking (weak-moderate-strong) & $0.403(0.22 I$ to 0.584$)$ & 0.001 \\
\hline Interactive intervention (yes vs no) & $-0.218(-0.47 \mid$ to 0.034$)$ & 0.09 \\
\hline Tailored intervention (yes vs no) & $0.450(0.185$ to 0.714$)$ & 0.001 \\
\hline Frequent messages (high vs low) & $-0.224(-0.606$ to -0.359$)$ & 0.025 \\
\hline Location of trial (less developed vs developed countries) & $-0.483(-0.606$ to -0.359$)$ & 0.001 \\
\hline
\end{tabular}

Note: The values in bold indicate $P<0.05$ (statistically significant value).

Abbreviations: eHealth, electronic health; EPHPP, Effective Public Health Practice Project; mHealth, mobile health; RR, risk ratio.

The duration of follow-up is a critical consideration. This review highlights the preponderance of studies of short-term abstinence (from 1 month to less than 6 months of follow-up) of web-based interventions and text messaging systems. Only two studies obtained substantially longer effects at 1 year of follow-up. Those interventions included a video-based computer-tailored program compared to a text-based version with brief generic text advice, ${ }^{85}$ and an internet and mobile phone-based version compared to printed material only. ${ }^{53}$ This is consistent with previous systematic reviews and confirms the promising impacts of technology-based interventions in behavioral change especially to sustain smoking cessation. ${ }^{18,22,23,28,142,143}$ Further investigations should be done to address the prolonged effect of the interventions.

After pooling findings from 67 internet smoking cessation studies, the strongest evidence of efficacy is for smoking cessation webpages compared to nonactive control conditions (no intervention, print materials only, assessment only) at 6 months of follow-up, and for joint pharmacotherapy plus web-based intervention. Previous reviews support the use of pharmacotherapy in combination with behavioral support, to improve cessation rates. ${ }^{21,144}$ Interactive and tailored web-based interventions have moderate effects on smoking abstinence compared to nonactive controls at 6 months or longer. ${ }^{20}$ This finding supports the efforts of health care providers and policymakers who seek to establish web-based smoking cessation interventions conjunctive with NRT. They may be especially helpful smokers in vulnerable groups, such as patients with HIV, COPD, and cancer and those undergoing treatment for substance use disorders.

When compared to active control groups or other eHealth modes, we could not find evidence of the effectiveness of internet-based tobacco cessation programs. This is consistent with an earlier Cochrane review, which concluded that eHealth smoking cessation interventions (eg, websites or text messages) may produce little or no increase in quitting compared to an active control group..$^{20,21}$ Among 12 eHealth smoking cessation interventions conducted with vulnerable patient groups, including five web-based, ${ }^{80,81,118,119,123}$ three text-messaging systems, ${ }^{84,98}$ and two computer-assisted programs, ${ }^{139,140}$ the subgroup analysis suggested that the web-based and tailored text messaging supports may increase cessation while computer-assisted interventions alone have little impact on smoking abstinence. This suggests that tobacco cessation interventions via mobile phone and other wireless devices probably offer the best uptake.

The effect size of web-based and mobile-based smoking intervention is moderated by methodologic quality. The efficacy of text message smoking cessation trials was affected by the location of study, which is the best in the USA, Canada, Europe, Australia, China, and Japan, and characteristics of interventions (eg, personalized message and frequency of SMS received). The present review suggests that stop-smoking interventions via websites and SMS with a weak quality of methodology are likely to overestimate the smoking cessation outcomes. It is possible to hypothesize that 
participants are less likely to disclose their smoking status if there is only self-report measurement without bioverification (as typically exists for internet smoking cessation programs). Additionally, according to the present synthesis, it is clear that trials are challenged by the difficulty of establishing doubleblinding in web-based environments. The participants may be aware of the allocated intervention trial conditions. If so, the effect size of eHealth interventions might be overestimated. Finally, a critical barrier for establishing effectiveness of online interventions is attrition bias, because the penalized imputation method is highly conservative (eg, missing cases are assumed to be continuing smokers). This problem was shown by Blankers et al (2016), where the estimated effects of internet-based smoking cessation interventions are more likely to overestimate outcomes in the conditions that have the higher retention rates. ${ }^{145}$

Among 24 mobile phone-based studies, 21 interventions utilized SMS-based reminders for smoking cessation and the three other studies provided counseling via cell phones for HIV-positive patients. ${ }^{117,122,123}$ Interestingly, all three mHealth programs for patients living with HIV/AIDS showed significant improvement in smoking abstinence at 3 months. Pooled, tailored text message interventions have a moderate effect on improving health behaviors. The strongest effect in mHealth experiments was contributed by nine studies that used tailored SMS. This emphasizes the benefits of tailoring the content of messages..$^{20,24,146,147}$ To maximize the effect of individually tailored messages, mHealth smoking cessation intervention should pay attention to selecting a negatively framed health message (eg, severe smoking harm), usually appropriate for those who have a high degree of nicotine dependence, or positively framed health message, targeting smokers who have lower nicotine dependence (eg, emphasizing well-being after quitting). ${ }^{148}$

This review found that effect sizes from mobile-based smoking cessation interventions were moderated by the frequency of texts. Four studies investigated the impact of SMS frequency and no significant difference was detected when comparing high-frequency vs low-frequency SMS groups. This is consistent with previous reviews that found that the effect of health behavior change interventions in general and smoking cessation programs, in particular, might not be influenced by the message frequency. ${ }^{24,27,149}$ Quantity of text messages may not be critical in determining smoking cessation outcomes, ${ }^{147}$ but rather the effects may vary in relation to personal preferences, as some smokers like to receive fewer SMS per day. ${ }^{150}$ Some participants may feel annoyed by multiple reminders per day, leading to negative results. Some studies have noted the importance of texting during critical times at high risk of cravings for smoking (eg, morning after wake-up), rather than sending texts randomly throughout the day. ${ }^{151}$

The role of health care providers is crucial for technologybased interventions such as mobile text messages or e-mails from clinicians, ${ }^{99}$ or computer-generated expert letters, ${ }^{84}$ or online resources supported by nurses ${ }^{72}$ to assist high-risk smokers to reduce and cease tobacco consumption. Programs provided largely by nurses, ${ }^{152}$ dentists, or physicians help to effectively foster patients' initial attempts to quit and help them consider using preferred smoking cessation technology platforms. ${ }^{153-155}$ For quit program developers it is often challenging to engage clinicians who are busy and not familiar with advanced technology. Clinicians may prefer face-to-face counseling that is coupled with eHealth interventions, with the goal of establishing rapport and improving communication between patients and practitioners.

\section{Limitations}

This review has limitations. First, with the rapid growth of technology, it was not possible for us to cover all studies and eHealth interventions worldwide. The English language criterion may also have restricted capture of international studies. Second, it was difficult to compare the overall effects across multiple studies because they calculated outcomes using different indicators (self-reported 7-day or 30-day PPA with or without biochemical validation) at different time points ( 24 hours, 7 days, 3 months, 6 months, and so on). The significant differences in study design and outcome indicators lead to high heterogeneity, and difficulty in pooling data on the effectiveness of some eHealth subgroups. Finally, this study did not take into account the contributions of user experience (eg, user satisfaction, perceived acceptability), which might moderate the effect size of eHealth/mHealth smoking cessation interventions.

\section{Conclusions}

This review found that smoking cessation interventions using web-based and mHealth approaches may increase cessation, but with moderate effects over short term periods. There is a clear need for more research in low- and middle-income countries. Considering all of the evidence together, the findings support the use of interactive, tailored, web-based and mobile phone-based smoking cessation interventions. Although the effect sizes are not high, even interventions that influence a minority of smokers to quit are worthwhile, as the cost per person is generally low. Policymakers should encourage 
the use of eHealth interventions by health professionals, and provide resources to ensure that expertise, intervention materials, and funded programs are authentic and sensitive to the characteristics and needs of target populations.

\section{Disclosure}

The authors report no conflicts of interest in this work.

\section{References}

1. Soriano JB, Abajobir AA, Abate KH, et al. Global, regional, and national deaths, prevalence, disability-adjusted life years, and years lived with disability for chronic obstructive pulmonary disease and asthma, 1990-2015: a systematic analysis for the Global Burden of Disease Study 2015. Lancet Respir Med. 2017;5(9):691-706.

2. World Health Organization. WHO report on the global tobacco epidemic 2009: implementing smoke-free environments; 2009. Available from: http://www.who.int/tobacco/en/. Accessed December 6, 2017.

3. Kreps GL, Neuhauser L. New directions in eHealth communication: opportunities and challenges. Patient Educ Couns. 2010;78(3): 329-336.

4. Ahern DK, Kreslake JM, Phalen JM, Bock B. What is eHealth (6): perspectives on the evolution of eHealth research. J Med Internet Res. 2006;8(1):e4.

5. Vogel MME, Combs SE, Kessel KA. mHealth and application technology supporting clinical trials: today's limitations and future perspective of smartRCTs. Front Oncol. 2017;7(3):37.

6. Kay M, Santos J, Takane M. mHealth New horizons for health through mobile technologies: based on the findings of the second global survey on eHealth; 2011.

7. Abroms LC, Boal AL, Simmens SJ, Mendel JA, Windsor RA. A randomized trial of Text2Quit: a text messaging program for smoking cessation. Am J Prev Med. 2014;47(3):242-250.

8. Augustson E, Engelgau MM, Zhang S, et al. Text to quit China: an mHealth smoking cessation trial. Am J Health Promot. 2016;31(3): $217-225$.

9. Bock B, Heron K, Jennings E, et al. A text message delivered smoking cessation intervention: the initial trial of TXT-2-Quit: randomized controlled trial. JMIR Mhealth Uhealth. 2013;1(2):e17.

10. Ferguson S, Walters J. The effect of mobile phone text messages for quitting smoking in motivated smokers: a randomised controlled trial. Eur Respir J. 2014;44(Suppl 58):P4454.

11. Ybarra M, Bağci Bosi AT, Korchmaros J, Emri S. A text messagingbased smoking cessation program for adult smokers: randomized controlled trial. J Med Internet Res. 2012;14(6):e172.

12. Ghorai K, Akter S, Khatun F, Ray P. mHealth for smoking cessation programs: a systematic review. J Pers Med. 2014;4(3):412-423.

13. Cashen MS, Dykes P, Gerber B. eHealth technology and Internet resources: barriers for vulnerable populations. J Cardiovasc Nurs. 2004; 19(3):209-214.

14. Park E, Drake E. Systematic review: Internet-based program for youth smoking prevention and cessation. J Nurs Scholarsh. 2015; 47(1):43-50.

15. Hutton HE, Wilson LM, Apelberg BJ, et al. A systematic review of randomized controlled trials: web-based interventions for smoking cessation among adolescents, college students, and adults. Nicotine Tob Res. 2011;13(4):227-238.

16. Balhara YS, Verma R. A review of web based interventions for managing tobacco use. Indian J Psychol Med. 2014;36(3):226-235.

17. Jayasekara R. Internet-based interventions for smoking cessation. Int $J$ Evid Based Healthc. 2011;9(2):195-195.

18. Shahab L, Mcewen A. Online support for smoking cessation: a systematic review of the literature. Addiction. 2009;104(11):1792-1804.

19. Graham A, Carpenter K, Cha S, et al. Systematic review and metaanalysis of Internet interventions for smoking cessation among adults. Subst Abuse Rehabil. 2016;7:55-69.
20. Taylor GMJ, Dalili MN, Semwal M, et al. Internet-based interventions for smoking cessation. Cochrane Database Syst Rev. 2017;47(2): CD007078.

21. Civljak M, Stead LF, Hartmann-Boyce J, Sheikh A, Car J. Internetbased interventions for smoking cessation. Cochrane Database Syst Rev. 2013;7:Cd007078.

22. Head KJ, Noar SM, Iannarino NT, Grant Harrington N. Efficacy of text messaging-based interventions for health promotion: a meta-analysis. Soc Sci Med. 2013;97:41-48.

23. Jardim C. Mobile phone-based interventions for smoking cessation. Sao Paulo Med J. 2010;128(2):106-107.

24. Whittaker R, Mcrobbie H, Bullen C, Rodgers A, Gu Y; Cochrane Tobacco Addiction Group. Mobile phone-based interventions for smoking cessation. Cochrane Database Syst Rev. 2016;17(Suppl 1):1-53.

25. Portnoy DB, Scott-Sheldon LAJ, Johnson BT, Carey MP. Computerdelivered interventions for health promotion and behavioral risk reduction: a meta-analysis of 75 randomized controlled trials, 1988-2007. Prev Med. 2008;47(1):3-16.

26. Haug S, Sannemann J, Meyer C, John U. Internet and mobile phone interventions to decrease alcohol consumption and to support smoking cessation in adolescents: a review. Gesundheitswesen. 2012;74(3): $160-177$.

27. Armanasco AA, Miller YD, Fjeldsoe BS, Marshall AL. Preventive health behavior change text message interventions: a meta-analysis. Am J Prev Med. 2017;52(3):391-402.

28. Chen Y-F, Madan J, Welton N, et al. Effectiveness and cost-effectiveness of computer and other electronic aids for smoking cessation: a systematic review and network meta-analysis. Health Technol Assess. 2012;16(38):1-205.

29. Moher D, Liberati A, Tetzlaff J, Altman DG, The PRISMA Group. Preferred reporting items for systematic reviews and meta-analyses: the PRISMA Statement. PLoS Med. 2009;6(7):e1000097.

30. Armijo-Olivo S, Stiles CR, Hagen NA, Biondo PD, Cummings GG. Assessment of study quality for systematic reviews: a comparison of the Cochrane Collaboration Risk of Bias Tool and the Effective Public Health Practice Project Quality Assessment Tool: methodological research. J Eval Clin Pract. 2012;18(1):12-18.

31. Hughes JR, Carpenter MJ, Naud S. Do point prevalence and prolonged abstinence measures produce similar results in smoking cessation studies? A systematic review. Nicotine Tob Res. 2010;12(7): 756-762.

32. Cheung KL, de Ruijter D, Hiligsmann M, et al. Exploring consensus on how to measure smoking cessation. A Delphi study. BMC Public Health. 2017;17(1):890.

33. Hughes JR, Keely J, Naud S. Shape of the relapse curve and long-term abstinence among untreated smokers. Addiction. 2004;99(1):29-38.

34. Gupta S. Intention-to-treat concept: a review. Perspect Clin Res. 2011; 2(3):109-112.

35. Fletcher J. What is heterogeneity and is it important? BMJ. 2007; 334(7584):94-96.

36. Balshem H, Helfand M, Schünemann HJ, et al. GRADE guidelines: 3 . Rating the quality of evidence. J Clin Epidemiol. 2011;64(4):401-406.

37. Danaher BG, Lichtenstein E, Mckay HG, Seeley JR. Use of non-assigned smoking cessation programs among participants of a Web-based randomized controlled trial. J Med Internet Res. 2009;11(2):e26.

38. Severson H, Gordon J, Danaher B, Akers L. ChewFree.com: evaluation of a web-based cessation program for smokeless tobacco users. Nicotine Tob Res. 2008;10(2):381-391.

39. Severson HH, Akers L, Andrews JA, Lichtenstein E, Jerome A. Evaluating two self-help interventions for smokeless tobacco cessation. Addict Behav. 2000;25(3):465-470.

40. Aveyard P, Sherratt E, Almond J, et al. The change-in-stage and updated smoking status results from a cluster-randomized trial of smoking prevention and cessation using the transtheoretical model among British adolescents. Prev Med. 2001;33(4):313-324.

41. Flay BR, Hansen WB, Johnson CA, et al. Implementation effectiveness trial of a social influences smoking prevention program using schools and television. Health Educ Res. 1987;2(4):385-400. 
42. Gordon JS, Mahabee-Gittens EM, Andrews JA, Christiansen SM, Byron DJ. A randomized clinical trial of a web-based tobacco cessation education program. Pediatrics. 2013;131(2):e455-e462.

43. Hollis JF, Polen MR, Whitlock EP, et al. Teen reach: outcomes from a randomized, controlled trial of a tobacco reduction program for teens seen in primary medical care. Pediatrics. 2005;115(4):981-989.

44. Lenert L, Munoz RF, Perez JE, Bansod A. Automated e-mail messaging as a tool for improving quit rates in an internet smoking cessation intervention. J Am Med Inform Assoc. 2004;11(4):235-240.

45. Prochaska JO, Velicer WF, Fava JL, et al. Counselor and stimulus control enhancements of a stage-matched expert system intervention for smokers in a managed care setting. Prev Med. 2001;32(1):23-32.

46. Seidman DF, Westmaas JL, Goldband S, et al. Randomized controlled trial of an interactive internet smoking cessation program with long-term follow-up. Ann Behav Med. 2010;39(1):48-60.

47. Hahn EJ, Rayens MK, Warnick TA, et al. A controlled trial of a quit and win contest. Am J Health Promot. 2005;20(2):117-126.

48. Linke SE, Rutledge T, Myers MG. Intermittent exercise in response to cigarette cravings in the context of an Internet-based smoking cessation program. Mental Health and Physical Activity. 2012;5(1):85-92.

49. Peng WB, Schoech D. Evaluation of a web-phone intervention system in changing smoking behavior - a randomized controlled trial. J Technol Hum Serv. 2013;31(3):248-268.

50. Reinwand DA, Crutzen R, Kienhuis AS, Talhout R, de Vries H. Website use and effects of online information about tobacco additives among the Dutch general population: a randomized controlled trial. J Med Internet Res. 2017;19(3): 60.

51. Shiffman S, Paty JA, Rohay JM, di Marino ME, Gitchell J. The efficacy of computer-tailored smoking cessation material as a supplement to nicotine polacrilex gum therapy. Arch Intern Med. 2000;160(11): 1675-1681.

52. Brendryen H, Drozd F, Kraft P. A digital smoking cessation program delivered through internet and cell phone without nicotine replacement (happy ending): randomized controlled trial. J Med Internet Res 2008a;10(5):e51.

53. Brendryen $H$, Kraft P. Happy ending: a randomized controlled trial of a digital multi-media smoking cessation intervention. Addiction. 2008b;103(3):478-484; discussion 485-476.

54. Elfeddali I, Bolman C, Candel MJJM, Wiers RW, de Vries H. Preventing smoking relapse via web-based computer-tailored feedback: a randomized controlled trial. J Med Internet Res. 2012;14(4):e109-e102.

55. Harrington KF, Kim Y-Il, Chen M, et al. Web-based intervention for transitioning smokers from inpatient to outpatient care. Am J Prev Med. 2016;51(4):620-629.

56. Mcdonnell DD, Kazinets G, Lee H-J, Moskowitz JM. An internet-based smoking cessation program for Korean Americans: results from a randomized controlled trial. Nicotine Tob Res. 2011;13(5):336-343.

57. Ray MN, Funkhouser E, Williams JH, et al. Smoking-cessation e-referrals: a national dental practice-based research network randomized controlled trial. Am J Prev Med. 2014;46(2):158-165.

58. Brown J, Michie S, Geraghty AW, et al. Internet-based intervention for smoking cessation (StopAdvisor) in people with low and high socioeconomic status: a randomised controlled trial. Lancet Respir Med. 2014;2(12):997-1006.

59. Smit ES, de Vries H, Hoving C. Effectiveness of a Web-based multiple tailored smoking cessation program: a randomized controlled trial among Dutch adult smokers. J Med Internet Res. 2012;14(3):e82.

60. Stoddard JL, Augustson EM, Moser RP. Effect of adding a virtual community (bulletin board) to smokefree.gov: randomized controlled trial. J Med Internet Res. 2008;10(5):e53.

61. Smit ES, Candel MJJM, Hoving C, de Vries H. Results of the PAS Study: a randomized controlled trial evaluating the effectiveness of a web-based multiple tailored smoking cessation program combined with tailored counseling by practice nurses. Health Commun. 2016;31(9): 1165-1173.

62. Etter J-F. Comparing the efficacy of two internet-based, computertailored smoking cessation programs: a randomized trial. J Med Internet Res. 2005;7(1):e2.
63. Oenema A, Brug J, Dijkstra A, de Weerdt I, de Vries H. Efficacy and use of an internet-delivered computer-tailored lifestyle intervention, targeting saturated fat intake, physical activity and smoking cessation: a randomized controlled trial. Ann Behav Med. 2008;35(2): $125-135$.

64. Bolman C, Eggers SM, van Osch L, Te Poel F, Candel M, de Vries H. Is action planning helpful for smoking cessation? Assessing the effects of action planning in a web-based computer-tailored intervention. Subst Use Misuse. 2015;50(10):1249-1260.

65. Brown J, Michie S, Geraghty AWA, et al. Internet-based intervention for smoking cessation (StopAdvisor) in people with low and high socioeconomic status: a randomised controlled trial. Lancet Respir Med. 2014;2(12):997-1006.

66. Swartz LHG, Noell JW, Schroeder SW, Ary DV. A randomised control study of a fully automated internet based smoking cessation programme. Tob Control. 2006;15(1):7-12.

67. Cameron D, Epton T, Norman P, et al. A theory-based online health behaviour intervention for new university students (U@Uni:LifeGuide): results from a repeat randomized controlled trial. Trials. 2015; 16(1):555.

68. Burford O, Jiwa M, Carter O, Parsons R, Hendrie D. Internet-based photoaging within Australian pharmacies to promote smoking cessation: randomized controlled trial. J Med Internet Res. 2013; 15(3):e64.

69. Calhoun PS, Datta S, Olsen M, et al. Comparative effectiveness of an Internet-based smoking cessation intervention versus clinic-based specialty care for veterans. J Subst Abuse Treat. 2016;69:19-27.

70. Lc A, Klatt C, Perry CL, et al. The RealU online cessation intervention for college smokers: a randomized controlled trial. Prev Med. 2008;47(2):194-199.

71. Mehring M, Haag M, Linde K, Wagenpfeil S, Schneider A. Effects of a guided web-based smoking cessation program with telephone counseling: a cluster randomized controlled trial. J Med Internet Res. 2014; 16(9):e218.

72. Pardavila-Belio MI, García-Vivar C, Pimenta AM, Canga-Armayor A, Pueyo-Garrigues S, Canga-Armayor N. Intervention study for smoking cessation in Spanish college students: pragmatic randomized controlled trial. Addiction. 2015;110(10):1676-1683.

73. Skov-Ettrup LS, Dalum P, Bech M, Tolstrup JS. The effectiveness of telephone counselling and internet- and text-message-based support for smoking cessation: results from a randomized controlled trial. Addiction. 2016;111(7):1257-1266.

74. Woodruff SI, Conway TL, Edwards CC, Elliott SP, Crittenden J. Evaluation of an Internet virtual world chat room for adolescent smoking cessation. Addict Behav. 2007;32(9):1769-1786.

75. Bannink R, Broeren S, Joosten-van Zwanenburg E, van As E, van de Looij-Jansen P, Raat H. Effectiveness of a web-based tailored intervention (E-health4Uth) and consultation to promote adolescents' health: randomized controlled trial. J Med Internet Res. 2014;16(5):e143.

76. Cobb NK, Jacobs MA, Wileyto P, Valente T, Graham AL. Diffusion of an evidence-based smoking cessation intervention through Facebook: a randomized controlled trial. Am J Public Health. 2016;106(6): 1130-1135.

77. Mañanes G, Vallejo MA. Usage and effectiveness of a fully automated, open-access, Spanish Web-based smoking cessation program: randomized controlled trial. J Med Internet Res. 2014;16(4):e111.

78. Mavrot C, Stucki I, Sager F, Etter J-F. Efficacy of an Internet-based, individually tailored smoking cessation program: a randomizedcontrolled trial. J Telemed Telecare. 2017;23(5):521-528.

79. Herbec A, Brown J, Tombor I, Michie S, West R. Pilot randomized controlled trial of an internet-based smoking cessation intervention for pregnant smokers ('MumsQuit)'. Drug Alcohol Depend. 2014;140: $130-136$.

80. Voncken-Brewster V, Tange H, de Vries H, Nagykaldi Z, Winkens B, van der Weijden T. A randomized controlled trial evaluating the effectiveness of a web-based, computer-tailored self-management intervention for\&nbsp;people\&nbsp; with or\&nbsp; at risk for COPD. Int $J$ Chron Obstruct Pulmon Dis. 2015;10:1061-1073. 
81. Zullig LL, Sanders LL, Shaw RJ, Mccant F, Danus S, Bosworth HB. A randomised controlled trial of providing personalised cardiovascular risk information to modify health behaviour. $J$ Telemed Telecare. 2014;20(3):147-152.

82. Emmons KM, Puleo E, Sprunck-Harrild K, et al. Partnership for health-2, a web-based versus print smoking cessation intervention for childhood and young adult cancer survivors: randomized comparative effectiveness study. J Med Internet Res. 2013;15(11):e218.

83. Clark MM, Cox LS, Jett JR, et al. Effectiveness of smoking cessation self-help materials in a lung cancer screening population. Lung Cancer. 2004;44(1):13-21.

84. Haug S, Meyer C, John U. Efficacy of an internet program for smoking cessation during and after inpatient rehabilitation treatment: a quasirandomized controlled trial. Addict Behav. 2011;36(12):1369-1372.

85. Stanczyk NE, de Vries H, Candel MJJM, Muris JWM, Bolman CAW. Effectiveness of video- versus text-based computer-tailored smoking cessation interventions among smokers after one year. Prev Med.2016; 82:42-50.

86. Graham AL, Papandonatos GD, Cobb CO, et al. Internet and telephone treatment for smoking cessation: mediators and moderators of shortterm abstinence. Nicotine Tob Res. 2015;17(3):299-308.

87. Houston TK, Sadasivam RS, Allison JJ, et al. Evaluating the QUITPRIMO clinical practice ePortal to increase smoker engagement with online cessation interventions: a national hybrid type 2 implementation study. Implementat Sci. 2015;10(1):154.

88. Wangberg SC, Nilsen O, Antypas K, Gram IT. Effect of tailoring in an internet-based intervention for smoking cessation: randomized controlled trial. J Med Internet Res. 2011;13(4):e121.

89. Dallery J, Raiff BR, Kim SJ, Marsch LA, Stitzer M, Grabinski MJ. Nationwide access to an internet-based contingency management intervention to promote smoking cessation: a randomized controlled trial. Addiction. 2016;112(5):875-883.

90. Fraser D, Kobinsky K, Smith SS, Kramer J, Theobald WE, Baker TB. Five population-based interventions for smoking cessation: a MOST trial. Transl Behav Med. 2014;4(4):382-390.

91. Mckay HG, Danaher BG, Seeley JR, Lichtenstein E, Gau JM. Comparing two web-based smoking cessation programs: randomized controlled trial. J Med Internet Res. 2008;10(5):e40.

92. Muñoz RF, Aguilera A, Schueller SM, Leykin Y, Pérez-Stable EJ. From online randomized controlled trials to participant preference studies: morphing the San Francisco Stop Smoking site into a worldwide smoking cessation resource. J Med Internet Res. 2012;14(3):e64

93. Muñoz RF, Barrera AZ, Delucchi K, Penilla C, Torres LD, PérezStable EJ. International Spanish/English Internet smoking cessation trial yields $20 \%$ abstinence rates at 1 year. Nicotine Tob Res. 2009; 11(9): 1025-1034.

94. Muñoz R, Lenert L, Delucchi K, et al. Toward evidence-based Internet interventions: a Spanish/English Web site for international smoking cessation trials. Nicotine Tob Res. 2006;8(1):77-87.

95. Stanczyk N, Bolman C, van Adrichem M, Candel M, Muris J, de Vries H. Comparison of text and video computer-tailored interventions for smoking cessation: randomized controlled trial. J Med Internet Res. 2014;16(3):e69.

96. Swan GE, Mcclure JB, Jack LM, et al. Behavioral counseling and varenicline treatment for smoking cessation. Am J Prev Med. 2010;38(5):482-490.

97. Choi SH, Waltje AH, Ronis DL, et al. Web-enhanced tobacco tactics with telephone support versus 1-800-QUIT-NOW telephone line intervention for operating engineers: randomized controlled trial. $J$ Med Internet Res. 2014;16(11): 255 .

98. Shuter J, Morales DA, Considine-Dunn SE, An LC, Stanton CA. Feasibility and preliminary efficacy of a web-based smoking cessation intervention for HIV-infected smokers. J Acquir Immune Defic Syndr. 2014;67(1):59-66.

99. Vilaplana J, Solsona F, Abella F, Cuadrado J, Alves R, Mateo J. S-PC: an e-treatment application for management of smoke-quitting patients. Comput Methods Programs Biomed. 2014;115(1):33-45.
100. Strecher VJ, Mcclure JB, Alexander GL, et al. Web-based smokingcessation programs - results of a randomized trial. Am J Prev Med. 2008;34(5):373-381.

101. Japuntich S, Zehner M, Smith S, et al. Smoking cessation via the Internet: a randomized clinical trial of an Internet intervention as adjuvant treatment in a smoking cessation intervention. Nicotine Tob Res. 2006;8(1):59-67.

102. Loughead J, Falcone M, Wileyto EP, et al. Can brain games help smokers quit?: results of a randomized clinical trial. Drug Alcohol Depend. 2016;168:112-118.

103. Humfleet GL, Hall SM, Delucchi KL, Dilley JW. A randomized clinical trial of smoking cessation treatments provided in HIV clinical care settings. Nicotine Tob Res. 2013;15(8):1436-1445. Available from: http://onlinelibrary.wiley.com/o/cochrane/clcentral/articles/438/ CN-00983438/frame.html

104. Patten CA, Croghan IT, Meis TM, et al. Randomized clinical trial of an Internet-based versus brief office intervention for adolescent smoking cessation. Patient Educ Couns. 2006;64(1-3):249-258.

105. Alessi SM, Rash CJ, Petry NM. A randomized trial of adjunct mHealth abstinence reinforcement with transdermal nicotine and counseling for smoking cessation. Nicotine Tob Res. 2016;19(3):290-298.

106. Borland R, Balmford J, Benda P. Population-level effects of automated smoking cessation help programs: a randomized controlled trial. Addiction. 2013;108(3):618-628.

107. Naughton F, Jamison J, Boase S, et al. Randomized controlled trial to assess the short-term effectiveness of tailored web- and text-based facilitation of smoking cessation in primary care (iQuit in practice). Addiction. 2014;109(7):1184-1193.

108. Bramley D, Riddell T, Whittaker R, et al. Smoking cessation using mobile phone text messaging is as effective in Maori as non-Maori. N Z Med J. 2005;118(1216):U1494.

109. Free C, Knight R, Robertson S, et al. Smoking cessation support delivered via mobile phone text messaging (txt2stop): a single-blind, randomised trial. Lancet. 2011;378(9785):49-55.

110. Free C, Whittaker R, Knight R, Abramsky T, Rodgers A, Roberts IG. Txt2stop: a pilot randomised controlled trial of mobile phone-based smoking cessation support. Tob Control. 2009;18(2):88-91.

111. Haug S, Schaub MP, Venzin V, Meyer C, John U. Efficacy of a text message-based smoking cessation intervention for young people: a cluster randomized controlled trial. J Med Internet Res. 2013;15(8):e171.

112. Müssener U, Bendtsen M, Karlsson N, White IR, Mccambridge J, Bendtsen P. Effectiveness of short message service text-based smoking cessation intervention among university students: a randomized clinical trial. JAMA Intern Med. 2016;176(3):321-328.

113. Rodgers A, Corbett T, Bramley D, et al. Do u smoke after txt? Results of a randomised trial of smoking cessation using mobile phone text messaging. Tob Control. 2005;14(4):255-261.

114. Shi HJ, Jiang XX, Yu CY, Zhang Y. Use of mobile phone text messaging to deliver an individualized smoking behaviour intervention in Chinese adolescents. J Telemed Telecare. 2013;19(5):282-287.

115. Whittaker R, Dorey E, Bramley D, et al. A theory-based video messaging mobile phone intervention for smoking cessation: randomized controlled trial. J Med Internet Res. 2011;13(1):e10-e72.

116. Ybarra ML, Holtrop JS, Prescott TL, Rahbar MH, Strong D. Pilot RCT results of stop my smoking USA: a text messaging-based smoking cessation program for young adults. Nicotine Tob Res. 2013;15(8): 1388-1399.

117. Gritz ER, Danysh HE, Fletcher FE, et al. Long-term outcomes of a cell phone-delivered intervention for smokers living with HIV/AIDS. Clin Infect Dis. 2013;57(4):608-615.

118. Naughton F, Cooper S, Foster K, et al. Large multicentre pilot randomized controlled trial testing a low-cost, tailored, self-help smoking cessation text message intervention for pregnant smokers (MiQuit). Addiction. 2017;112(7):1238-1249.

119. Naughton F, Prevost AT, Gilbert H, Sutton S. Randomized controlled trial evaluation of a tailored leaflet and SMS text message self-help intervention for pregnant smokers (MiQuit). Nicotine Tob Res. 2012;14(5):569-577. 
120. Pollak KI, Lyna P, Bilheimer A, et al. A pilot study testing SMS text delivered scheduled gradual reduction to pregnant smokers. Nicotine Tob Res. 2013;15(10):1773-1776.

121. Shelley D, Tseng TY, Gonzalez M, et al. Correlates of adherence to varenicline among HIV+ smokers. Nicotine Tob Res. 2015;17(8): 968-974.

122. Vidrine DJ, Arduino RC, Lazev AB, Gritz ER. A randomized trial of a proactive cellular telephone intervention for smokers living with HIV/AIDS. AIDS. 2006;20(2):253-260.

123. Vidrine DJ, Kypriotakis G, Li L, et al. Mediators of a smoking cessation intervention for persons living with HIV/AIDS. Drug Alcohol Depend. 2015;147:76-80.

124. Hicks TA, Thomas SP, Wilson SM, Calhoun PS, Kuhn ER, Beckham JC. A preliminary investigation of a relapse prevention mobile application to maintain smoking abstinence among individuals with posttraumatic stress disorder. J Dual Diagn. 2017;13(1):1-6.

125. Dan M, Grabinski MJ, Raiff BR. Smartphone-based contingency management for smoking cessation with smokers diagnosed with attention-deficit/hyperactivity disorder. Transl Issues Psychol Sci 2016;2(2):116-127.

126. Bricker JB, Mull KE, Kientz JA, et al. Randomized, controlled pilot trial of a smartphone app for smoking cessation using acceptance and commitment therapy. Drug Alcohol Depend. 2014;143:87-94.

127. Balmford J, Borland R, Benda P, Howard S. Factors associated with use of automated smoking cessation interventions: findings from the eQuit study. Health Educ Res. 2013;28(2):288-299.

128. Borland R, Balmford J, Hunt D. The effectiveness of personally tailored computer-generated advice letters for smoking cessation. Addiction. 2004;99(3):369-377.

129. Hoving C, Mudde AN, Dijk F, de Vries H. Effectiveness of a smoking cessation intervention in Dutch pharmacies and general practices. Health Educ. 2010;110(1):17-29.

130. Meyer C, Ulbricht S, Gross B, et al. Adoption, reach and effectiveness of computer-based, practitioner delivered and combined smoking interventions in general medical practices: a three-arm cluster randomized trial. Drug Alcohol Depend. 2012;121(1-2):124-132.

131. Meyer C, Ulbricht S, Haug S, et al. Motivating smokers to quit using computer-generated letters that target either reduction or cessation: a population-based randomized controlled trial among smokers who do not intend to quit. Drug Alcohol Depend. 2016;166:177-186.

132. Prochaska JO, Velicer WF, Fava JL, Rossi JS, Tsoh JY. Evaluating a population-based recruitment approach and a stage-based expert system intervention for smoking cessation. Addict Behav. 2001; 26(4):583-602

133. Riley W, Jerome A, Behar A, Weil J. Computer and manual self-help behavioral strategies for smoking reduction: initial feasibility and one-year follow-up. Nicotine Tob Res. 2002;4(Suppl 2):S183-S188.

134. Schumann A, John U, Baumeister SE, Ulbricht S, Rumpf HJ, Meyer C. Computer-tailored smoking cessation intervention in a general population setting in Germany: outcome of a randomized controlled trial. Nicotine Tob Res. 2008;10(2):371-379.

135. Sutton S, Gilbert H. Effectiveness of individually tailored smoking cessation advice letters as an adjunct to telephone counselling and generic self-help materials: randomized controlled trial. Addiction 2007;102(6):994-1000.

136. Wetter DW, Mcclure JB, Cofta-Woerpel L, et al. A randomized clinical trial of a palmtop computer-delivered treatment for smoking relapse prevention among women. Psychol Addict Behav. 2011;25(2): $365-371$.

137. O’Neill HK, Gillispie MA, Slobin K. Stages of change and smoking cessation: a computer-administered intervention program for young adults. Am J Health Promot. 2000;15(2):93-96.
138. Prokhorov AV, Yost T, Mullin-Jones M, et al. "Look at your health": outcomes associated with a computer-assisted smoking cessation counseling intervention for community college students. Addict Behav. 2008;33(6):757-771.

139. Lawrence T, Aveyard P, Cheng KK, Griffin C, Johnson C, Croghan E. Does stage-based smoking cessation advice in pregnancy result in long-term quitters? 18-month postpartum follow-up of a randomized controlled trial. Addiction. 2005;100(1):107-116.

140. Unrod M, Smith M, Spring B, Depue J, Redd W, Winkel G. Randomized controlled trial of a computer-based, tailored intervention to increase smoking cessation counseling by primary care physicians. J Gen Intern Med. 2007;22(4):478-484.

141. Tsoh JY, Kohn MA, Gerbert B. Promoting smoking cessation in pregnancy with Video Doctor plus provider cueing: a randomized trial. Acta Obstet Gynecol Scand. 2010;89(4):515-523.

142. Brown J. A review of the evidence on technology-based interventions for the treatment of tobacco dependence in college health. Worldviews Evid Based Nurs. 2013;10(3):150-162.

143. Whittaker R, Mcrobbie H, Bullen C, Borland R, Rodgers A, Gu Y. Mobile phone-based interventions for smoking cessation. Cochrane Database Syst Rev. 2012;11:Cd006611.

144. Hartmann-Boyce J, Stead LF, Cahill K, Lancaster T. Efficacy of interventions to combat tobacco addiction: Cochrane update of 2012 reviews. Addiction. 2013;108(10):1711-1721.

145. Blankers M, Smit ES, van der Pol P, de Vries H, Hoving C, van Laar M. The missing=smoking assumption: a fallacy in internet-based smoking cessation trials? Nicotine Tob Res. 2016;18(1):25-33.

146. Skov-Ettrup LS, Ringgaard LW, Dalum P, Flensborg-Madsen T, Thygesen LC, Tolstrup JS. Comparing tailored and untailored text messages for smoking cessation: a randomized controlled trial among adolescent and young adult smokers. Health Educ Res. 2014;29(2): 195-205.

147. Kong G, Ells DM, Camenga DR, Krishnan-Sarin S. Text messagingbased smoking cessation intervention: a narrative review. Addict Behav. 2014;39(5):907-917.

148. Moorman M, van den Putte B. The influence of message framing, intention to quit smoking, and nicotine dependence on the persuasiveness of smoking cessation messages. Addict Behav. 2008;33(10):1267-1275.

149. Orr JA, King RJ. Mobile phone SMS messages can enhance healthy behaviour: a meta-analysis of randomised controlled trials. Health Psychol Rev. 2015;9(4):397-416.

150. Bock BC, Heron KE, Jennings EG, Magee JC, Morrow KM. User preferences for a text message-based smoking cessation intervention. Health Educ Behav. 2013;40(2):152-159.

151. Jamison J, Naughton F, Gilbert H, Sutton S. Delivering smoking cessation support by mobile phone text message: what information do smokers want? A focus group study. J Appl Biobehav Res. 2013; 18(1):1-23

152. Kazemzadeh Z, Manzari ZS, Pouresmail Z. Nursing interventions for smoking cessation in hospitalized patients: a systematic review. Int Nurs Rev. 2017;64(2):263-275.

153. WHO. The role of health professionals in tobacco control. France; 2005. Available from: http:/www.who.int/tobacco/resources/publications/ wntd/2005/bookletfinal_20april.pdf. Accessed February 12, 2018.

154. Greenhalgh E, Stillman S, Ford C. 7.10 Role of health professionals and social services. In: Scollo MaW MH, editor. Tobacco in Australia: Facts and issues. Melbourne: Cancer Council Victoria; 2016.

155. Eapen ZJ, Peterson ED. Can mobile health applications facilitate meaningful behavior change?: Time for answers. JAMA. 2015;314(12) 1236-1237. 
Video abstract

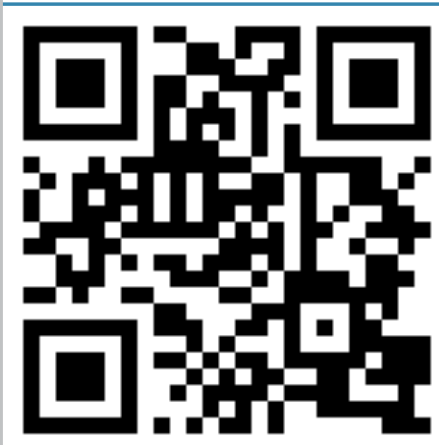

Point your SmartPhone at the code above. If you have a QR code reader the video abstract will appear. Or use:

http://youtu.be/GrU038xCYbM

Patient Preference and Adherence

Dovepress

\section{Publish your work in this journal}

Patient Preference and Adherence is an international, peer-reviewed, open access journal that focuses on the growing importance of patient preference and adherence throughout the therapeutic continuum. Patient satisfaction, acceptability, quality of life, compliance, persistence and their role in developing new therapeutic modalities and compounds to optimize

clinical outcomes for existing disease states are major areas of interest for the journal. This journal has been accepted for indexing on PubMed Central. The manuscript management system is completely online and includes a very quick and fair peer-review system, which is all easy to use. Visit http://www dovepress.com/testimonials.php to read real quotes from published authors.

Submit your manuscript here: http://www.dovepress.com/patient-preference-and-adherence-journal 